\title{
Ferric Carboxymaltose for Anemic Perioperative Populations: A Systematic Literature Review of Randomized Controlled Trials
}

\author{
John Jeffrey Jones (1D' \\ Linda M Mundy $\mathbb{D}^{2}$ \\ Nicole Blackman $\mathbb{D}^{2}$ \\ Michelle Shwarz $\mathbb{D D}^{2}$ \\ 'College of Pharmacy and Health \\ Sciences, St. John's University, Queens, \\ NY, USA; ${ }^{2}$ American Regent, Inc, \\ Norristown, PA, USA
}

Correspondence: Nicole Blackman American Regent, Inc, 800 Adams Avenue, Suite 200, Norristown, PA, 19403, USA

Tel + I 63I 7723524

Email nblackman@americanregent.com
Importance: Perioperative anemia is a common comorbid condition associated with increased risk of morbidity and mortality in patients undergoing elective surgical procedures. Objective: We conducted a systematic literature review (SLR) to determine the efficacy and safety of the use of intravenous ferric carboxymaltose (FCM) for the treatment of perioperative anemia in preoperative, intraoperative, and postoperative elective surgical care.

Evidence Review: Studies meeting inclusion criteria for the SLR reported on treatment efficacy in an adult study population randomly allocated to FCM for the treatment of perioperative anemia during the perioperative period. After screening, 10 of 181 identified studies from searches in MEDLINE and EMBASE databases were identified for inclusion in this review.

Findings: Preoperative treatment was reported in six studies, intraoperative treatment in one study, postoperative treatment in two studies, and both pre- and postoperative treatment in one study. Together, 1975 patients were studied, of whom 943 were randomized to FCM, of whom 914 received FCM treatment. The 10 studies reported elective surgical populations for colorectal, gastric, orthopedic, abdominal, urologic, plastic, neck, gynecologic, and otolaryngologic procedures. Given the clinical and methodological heterogeneity of the studies, the analyses were limited to qualitative assessments without meta-analyses. All 10 studies reported statistically greater changes in hemoglobin concentration, serum ferritin, and/or transferrin saturation with FCM treatment compared with comparators (placebo, oral iron, standard care, or a combination of these). Two studies reported statistically significant differences in transfusion rate and 2 studies reported significant differences in length of hospital stay between FCM and its comparator(s).

Conclusions and Relevance: This SLR adds to existing data that administration of FCM in preoperative and postoperative settings improves hematologic parameters. Several studies in the review supported the beneficial effects of FCM in reducing transfusion rate and length of stay. Larger, well-designed, longer-term studies may be needed to further establish the efficacy and safety of FCM in elective surgery patients with perioperative anemia.

Keywords: intravenous iron, hemoglobin, elective surgery, patient blood management, irondeficiency anemia

\section{Plain Language Summary}

Preoperative and postoperative anemia occur frequently in patients undergoing elective surgery. ${ }^{1}$

Perioperative anemia is associated with an increased risk of morbidity, mortality, and other adverse postoperative outcomes. ${ }^{1-4}$ 
Iron deficiency is a common cause of anemia in surgical patients, affecting at least $10 \%$ of surgical patients during the preoperative period and at least $20 \%$ during the postoperative period. ${ }^{5,6}$

Blood transfusion is frequently administered as part of the standard of care for perioperative anemia ${ }^{7}$ and may produce a temporary increase in hemoglobin levels ${ }^{8}$ but is associated with poor outcomes. ${ }^{9}$

This systematic review evaluated the effectiveness and safety of ferric carboxymaltose in patients with perioperative anemia, with a focus on patients' health states during the preoperative and postoperative period.

The 10 identified studies included patient populations undergoing elective colorectal, gastric, orthopedic, abdominal, urologic, plastic, neck, gynecologic, and otolaryngologic procedures.

Comparators were placebo, oral iron, standard care, or a combination of these interventions.

Overall, this review found that ferric carboxymaltose significantly increased hemoglobin level, serum ferritin concentrations, and transferrin saturation in patients with perioperative anemia who were undergoing elective surgery.

\section{Introduction}

Perioperative anemia is a common comorbid condition associated with increased risk of morbidity and mortality in patients undergoing elective surgical procedures. The most common etiology of perioperative anemia in adults is iron deficiency. Clinical signs and symptoms of iron-deficiency anemia (IDA) are protean and vary widely, and perioperative health outcomes associated with IDA include reduced physical function, prolonged postoperative recovery, increased length of hospital stay, and mortality. ${ }^{1-4,10}$ Among orthopedic patients, the preoperative prevalence of anemia is estimated at $24 \%$ to $44 \%$, and postoperative estimates are significantly higher. ${ }^{1}$ Among patients with advanced colon cancer undergoing colectomy, the estimated prevalence of anemia is reported to be as high as $75.8 \%{ }^{11}$

In preoperative evaluation for IDA, diagnostic assessment and pre-surgical treatment varies. One recognized intervention is blood transfusion, with an estimated 6.6 million red blood cell (RBC) units administered annually to elective surgery patients in the United States. ${ }^{4}$ To assess the use of an intravenous iron in anemic perioperative patient populations, a systematic literature review (SLR) was conducted and focused on the safety and efficacy of ferric carboxymaltose.

\section{Methods}

\section{Study Design}

The study protocol was designed and executed according to the Preferred Reporting Items for Systematic Reviews and Meta-Analyses (PRISMA). ${ }^{12}$ All review methods were conducted a priori according to the established protocol. Publication screening, selection, and assessments of bias were carried out by the authors, with consensus for reconciliation. Included studies were conducted in adults ( $\geq 18$ years of age) with anemia (if not IDA) who had been identified for elective surgery and randomly allocated to receive intravenous (IV) FCM or comparator(s). Inclusion also required study publication in peerreviewed journals. Studies were excluded if the design was nonexperimental, if efficacy was not reported, or if the investigative treatment consisted of only IV FCM in combination with either erythropoietin or an erythropoiesis-stimulating agent; animal and pediatric studies were also excluded. Conference abstracts and grey literature were excluded.

\section{Literature Search}

Comprehensive, computer-based literature searches for records were performed systematically using the MEDLINE (PubMed, US National Library of Medicine, National Institutes of Health) and EMBASE databases. The electronic search strategy was peer reviewed and developed with guidance from a university librarian at St. John's University College of Pharmacy and Health Sciences. Databases were searched from their inception to January 2021 for abbreviations and full-phrase versions of keywords and Medical Subject Headings combined with Boolean operators as outlined in the Supplementary Data, Appendix 1. Two reviewers independently and in duplicate assessed titles and abstracts of identified records for trial eligibility, and a third reviewer resolved any discrepancies by discussion or adjudication until consensus was reached. Relevant records were further assessed by examining the full-text articles. A snowball method (using a key manuscript as a starting point and consulting the bibliography to find other relevant titles on the subject) was used to search the identified literature to additional studies. Data were extracted onto a standardized extraction form. 


\section{Risk of Bias and Quality Assessment}

Internal validity and risk of bias for each study meeting final inclusion criteria were assessed in duplicate by 2 independent reviewers using the Cochrane Risk of Bias Tool. ${ }^{13}$ The key types of bias that were examined were selection, performance, detection, attrition, and reporting. The overall quality of evidence was assessed using the Grading of Recommendations Assessment, Development, and Evaluation (GRADE) ${ }^{14}$ approach to determine the strength of the conclusions/recommendations from this review.

\section{Outcome Measures}

The primary outcomes were the absolute or relative change from baseline in hemoglobin $(\mathrm{Hb})$ concentration $(\mathrm{g} / \mathrm{dL})$, serum ferritin $(\mathrm{ng} / \mathrm{mL})$, and $\%$ transferrin saturation (TSAT). Primary outcomes that were reported in alternative units were converted for consistency across studies for ease of interpretability; conversions were quality controlled for accuracy. Secondary outcome measures were the proportion of patients who received a perioperative blood transfusion, the occurrence of adverse events, treatment-related adverse events, postoperative mortality, length of hospital stay, and any validated measure of quality of life (QOL).

\section{Results}

\section{Study Selection}

We identified 244 citations, 208 through database searching and 36 through other sources. The number was decreased to 181 after removing duplicates (Figure 1). The 181 citations were screened based on title and abstract, and 139 were excluded. After screening the fulltext articles of the remaining 42 citations, 32 were excluded. Ultimately, 10 eligible studies were included in this systematic review.

\section{Study Characteristics}

All 10 studies included in the systematic review were randomized clinical trials and were published between 2014 and 2020. ${ }^{7,15-23}$ Five studies were conducted in Europe (United Kingdom, ${ }^{15,21,23}$ Spain $^{15,16}$ ), 2 studies in Oceania (Australia ${ }^{7,17}$ ), and 3 studies in Asia (South Korea $\left.^{19,20,22}\right)$.

The design and patient flow of the included studies are summarized in Table 1. Studies investigated the use of FCM in the following surgical populations: cancer (colorectal, ${ }^{18}$ gastric ${ }^{19}$ ), cardiac, ${ }^{21}$ menorrhagia, ${ }^{20}$ orthopedic (hip arthroplasty, ${ }^{16,22}$ total knee arthroplasty ${ }^{15,22}$ ), abdominal, ${ }^{17,23}$ and a combination of orthopedic, abdominal, neck, gynecologic, urologic, plastic, and ear, nose, and throat (ENT) ${ }^{7}$ Ferric carboxymaltose was administered preoperatively in 5 studies, ${ }^{16,18,20,21,23}$ intraoperatively in 1 study, ${ }^{22}$ postoperatively in 3 studies, ${ }^{7,15,19}$ and perioperatively (both preoperatively and postoperatively) in 1 study. $^{17}$ With respect to blinding, 2 studies used a double-blind design, ${ }^{16,23} 3$ were single-blind, ${ }^{15,19,22}$ and 5 were open-label. ${ }^{7,17,18,20,21}$ Follow-up periods for patients varied, spanning from 2 weeks post-infusion, ${ }^{20} 4$ weeks postoperatively ${ }^{15,17,22}$ to 2 to 6 months after hospital discharge. $7,15,16,19,21,23$

In total, 1975 study patients were randomized across the 10 studies, 943 (48\%) of whom were randomized to receive IV FCM, and of these, 914 (97\%) received their assigned treatment. Three studies compared IV FCM with oral ferrous sulfate (dose: $100 \mathrm{mg}$ per day ${ }^{15}$ to $200 \mathrm{mg}$ twice daily ${ }^{15,21}$ ), 1 study compared IV FCM with IV iron sucrose (dose: $200 \mathrm{mg}$ iron $\mathrm{x} 3$ /week), ${ }^{20}$ and 2 studies compared IV FCM with standard of care (no intervention ${ }^{7}$ or no treatment, continued observations, oral iron recommendations, and allogeneic blood transfusion $[\mathrm{ABT}]) .{ }^{17}$ The comparator for 3 of the remaining 4 studies was IV saline placebo, ${ }^{19,22,23}$ and the comparators for the other remaining study (triple-arm, parallel design) were $1 \mathrm{~mL}$ subcutaneous (SC) saline placebo with $250 \mathrm{~mL}$ of IV saline placebo and 40,000 IU/1 mL SC erythropoietin (EPO) with $1000 \mathrm{mg}$ IV FCM diluted in $250 \mathrm{~mL}$ saline. ${ }^{16}$ The dosages of IV FCM across studies varied in terms of total dose and dosage calculation as well as administration time, which spanned 6 to 30 minutes. In 3 studies, IV FCM was given in a single dose of $1000 \mathrm{mg} ; ;^{7,22,23}$ in the 7 others, the dose was determined by the Ganzoni formula to correct the total iron deficit, ${ }^{15}$ manufacturer recommendation $(15 \mathrm{mg} / \mathrm{kg}))^{7,17}$ weight cutoffs $(<50$ or $\geq 50 \mathrm{~kg}),{ }^{19,20}$ weight cutoffs in combination with inclusion Hb values, ${ }^{18,21}$ or blood loss ( $\left.5 \times 10^{-7} \mathrm{mcg} / \mathrm{L}\right)$ if blood loss was $\geq 100 \mathrm{~mL} .{ }^{17}$ For 8 of the 10 studies, the maximum single dose of IV FCM was $1000 \mathrm{mg} ;{ }^{7,15-17,19,22,23}$ Keeler et al and Padmanabhan et al allowed a maximum total dose of up to $2000 \mathrm{mg}$ ( 2 doses of $1000 \mathrm{mg}$ administered 7 days apart and when required). ${ }^{15,21}$

The hematologic inclusion criteria varied among the studies, with 5 requiring IDA with $\mathrm{Hb}$ limits $\left(9-12 \mathrm{~g} / \mathrm{dL},{ }^{16}\right.$ $<11 \mathrm{~g} / \mathrm{dL}$ [women] or $<12 \mathrm{~g} / \mathrm{dL}$ [men], ${ }^{18}<12 \mathrm{~g} / \mathrm{dL}$ [women] or $<13 \mathrm{~g} / \mathrm{dL}[\mathrm{men}]^{21,23}$ and $\left.\geq 7-<10 \mathrm{~g} / \mathrm{dL}^{19}\right) ; 4$ requiring IDA with specific hematologic profiles (serum 


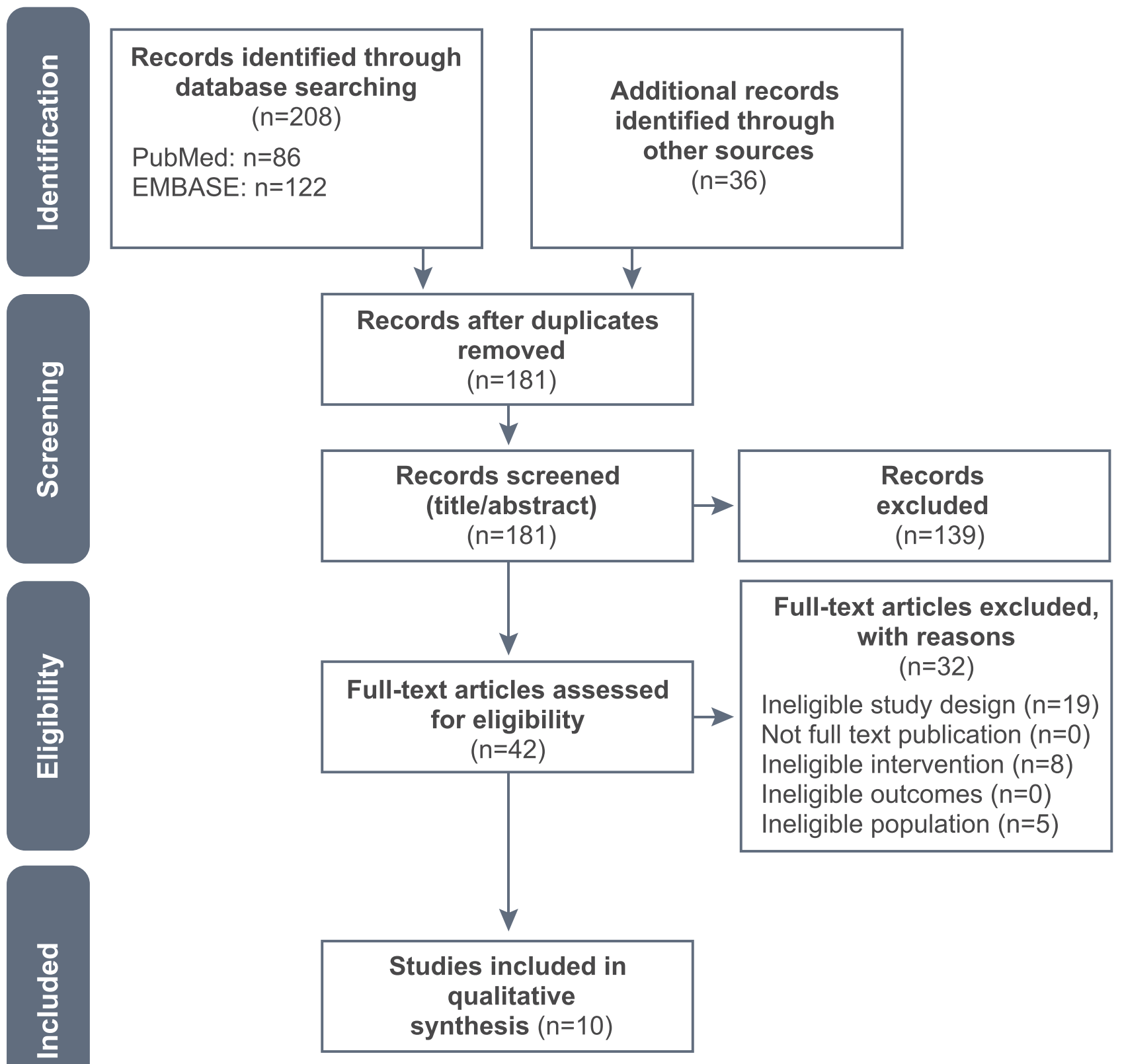

Figure I Preferred Reporting Items for Systematic Reviews and Meta-Analyses flowchart of the study selection process.

Note: Adapted from Page MJ, Moher D, Bossuyt PM, et al. PRISMA 2020 explanation and elaboration: updated guidance and exemplars for reporting systematic reviews. BMJ. 2021;372:n $160 .^{37}$

ferritin $<300 \mu \mathrm{g} / \mathrm{L}$, transferrin saturation $<25 \%$, and $\mathrm{Hb}$ $<12 \mathrm{~g} / \mathrm{dL}$ [women] or $<13 \mathrm{~g} / \mathrm{dL}$ [men]; ${ }^{17} \mathrm{Hb} 7-12 \mathrm{~g} / \mathrm{dL}$ with serum ferritin $\leq 100 \mu \mathrm{g} / \mathrm{L}$ or TSAT $\leq 20 \%{ }^{7}$ serum ferritin $<300 \mu \mathrm{g} / \mathrm{L}$ and $\mathrm{Hb}<10 \mathrm{~g} / \mathrm{dL}),{ }^{20,22}$ and 1 requiring anemia and/or IDA with a specific hematologic profile ( $\mathrm{Hb}$ $8.5-12 \mathrm{~g} / \mathrm{dL}$, TSAT $<20 \%$, or both ${ }^{15}$ ).
Institution-specific medical care standards specifically relating to perioperative blood management (PBM) were explicitly stated in 3 of the 10 studies. ${ }^{15-17}$ The first study used thromboprophylaxis with low-molecular-weight heparin and prophylaxis with proton pump inhibitors for upper gastrointestinal bleeding. ${ }^{16}$ The second used 


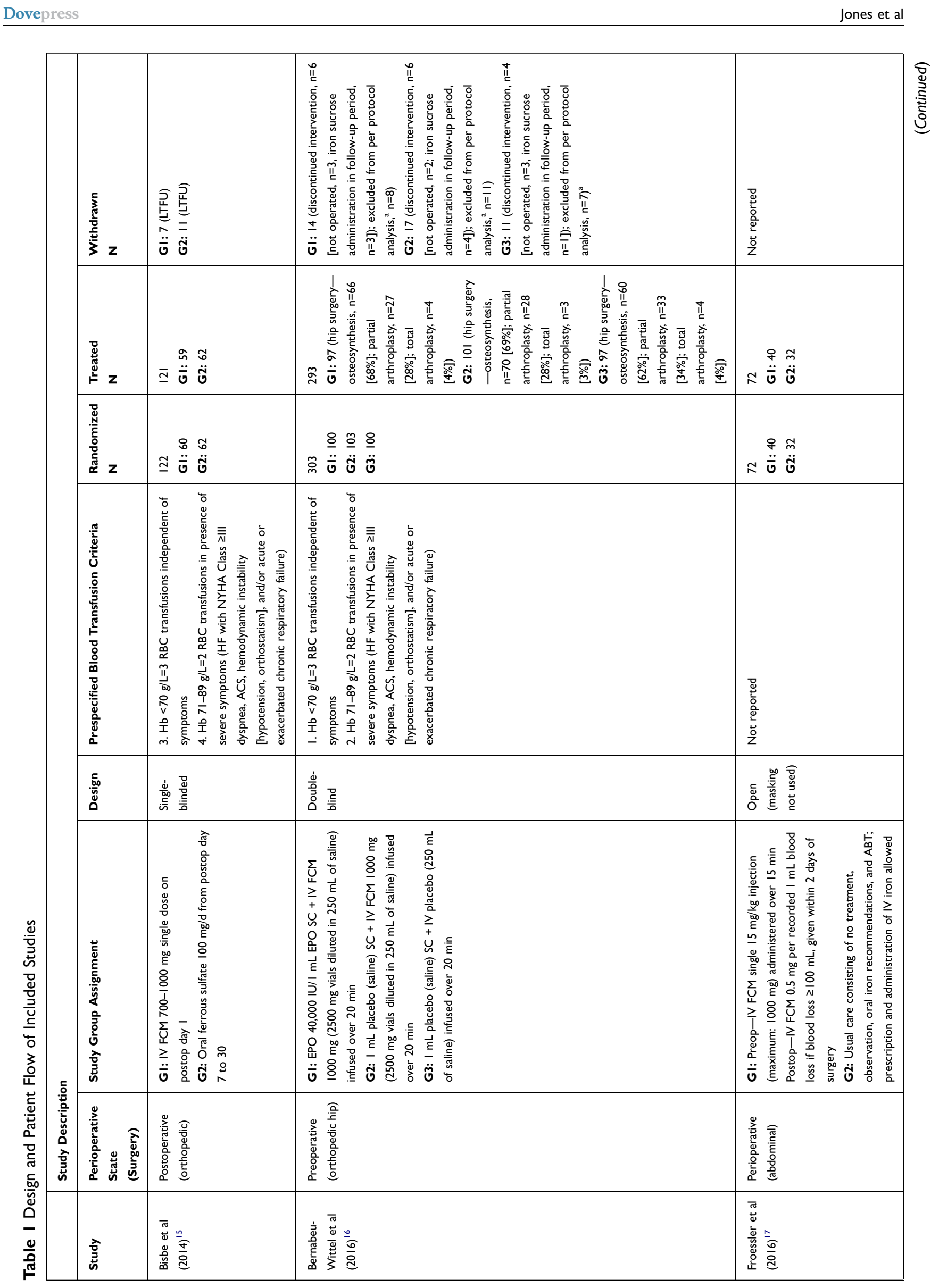

Journal of Blood Medicine 202 I:I2

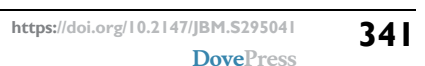




\begin{tabular}{|c|c|c|c|c|c|}
\hline & 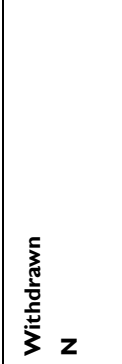 & 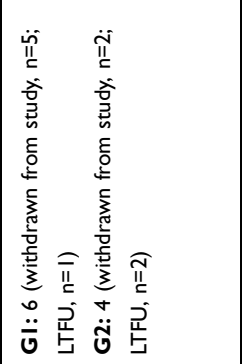 & 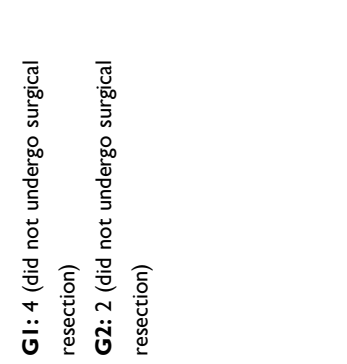 & 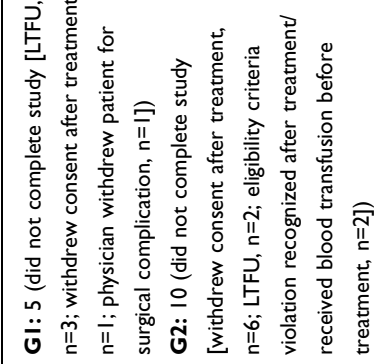 & 弟 \\
\hline & 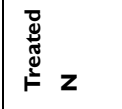 & 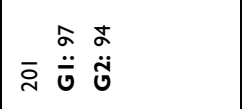 & 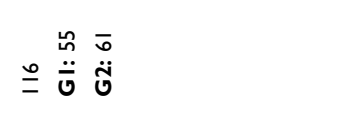 & 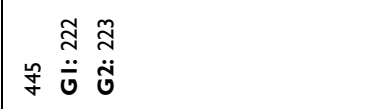 & 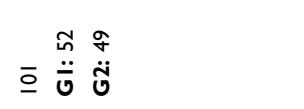 \\
\hline & 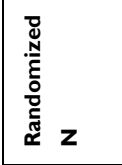 & 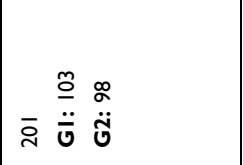 & 요요 & 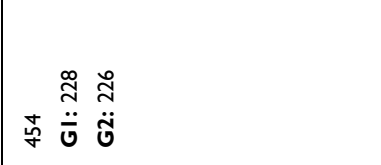 & 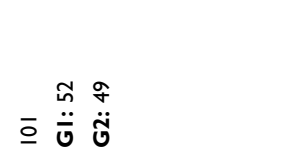 \\
\hline & 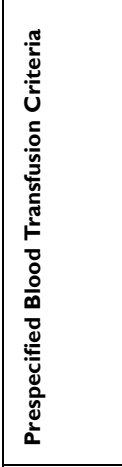 & 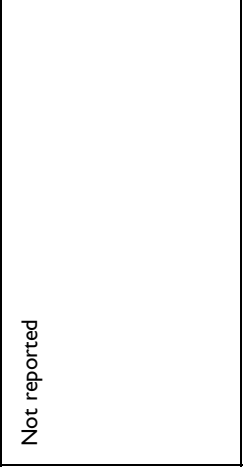 & 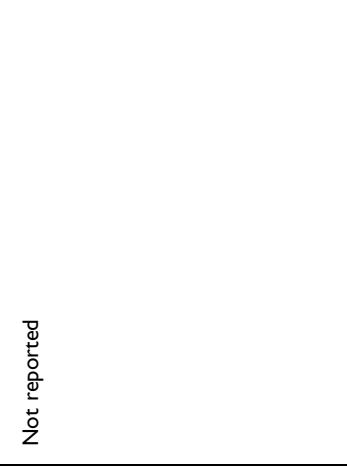 & 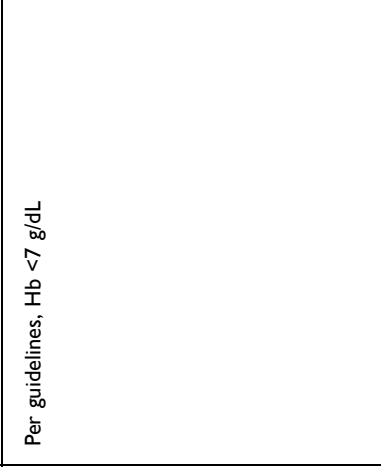 & 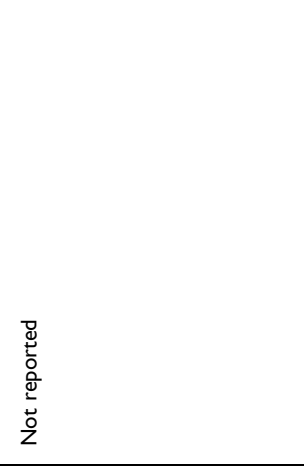 \\
\hline & 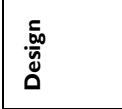 & 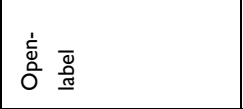 & 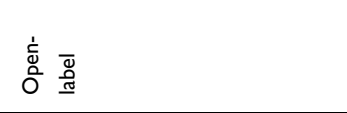 & 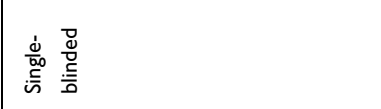 & 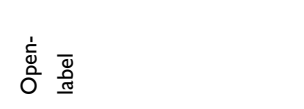 \\
\hline & 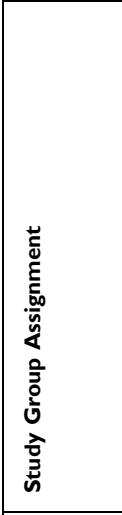 & 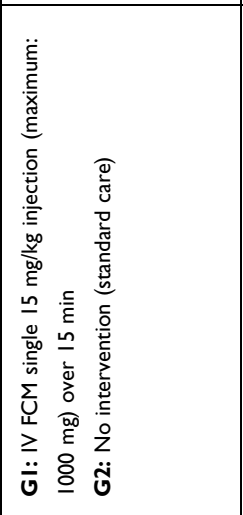 & 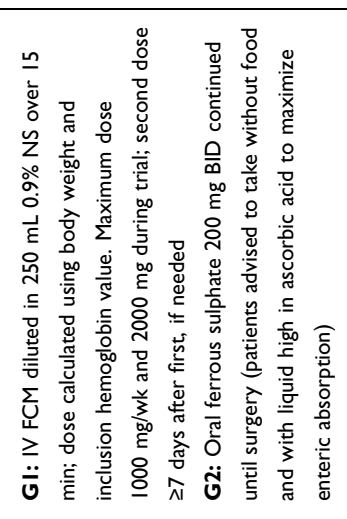 & 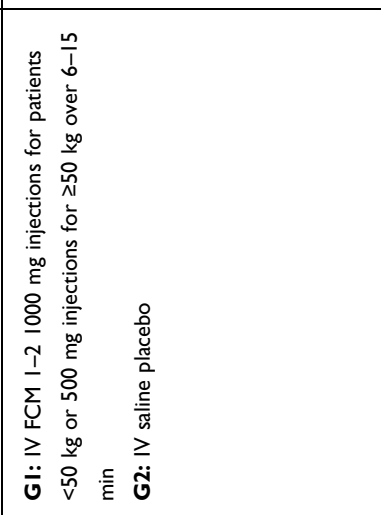 & 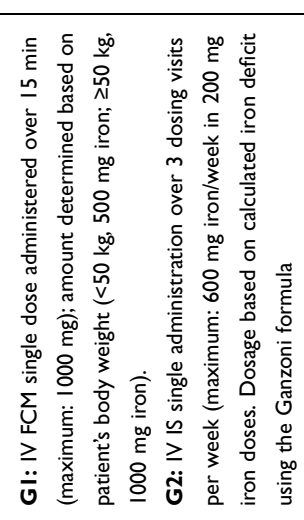 \\
\hline 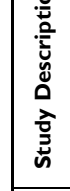 & 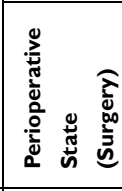 & 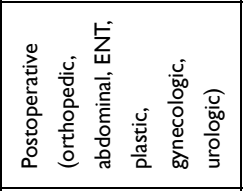 & 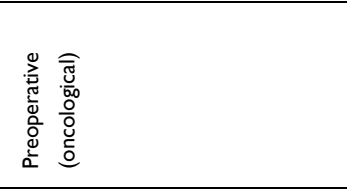 & 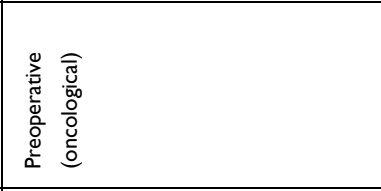 & 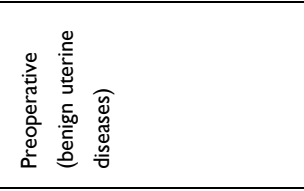 \\
\hline & 耪 & 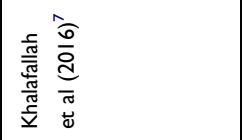 & 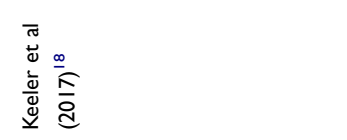 & 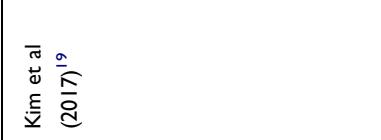 & 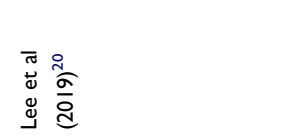 \\
\hline
\end{tabular}




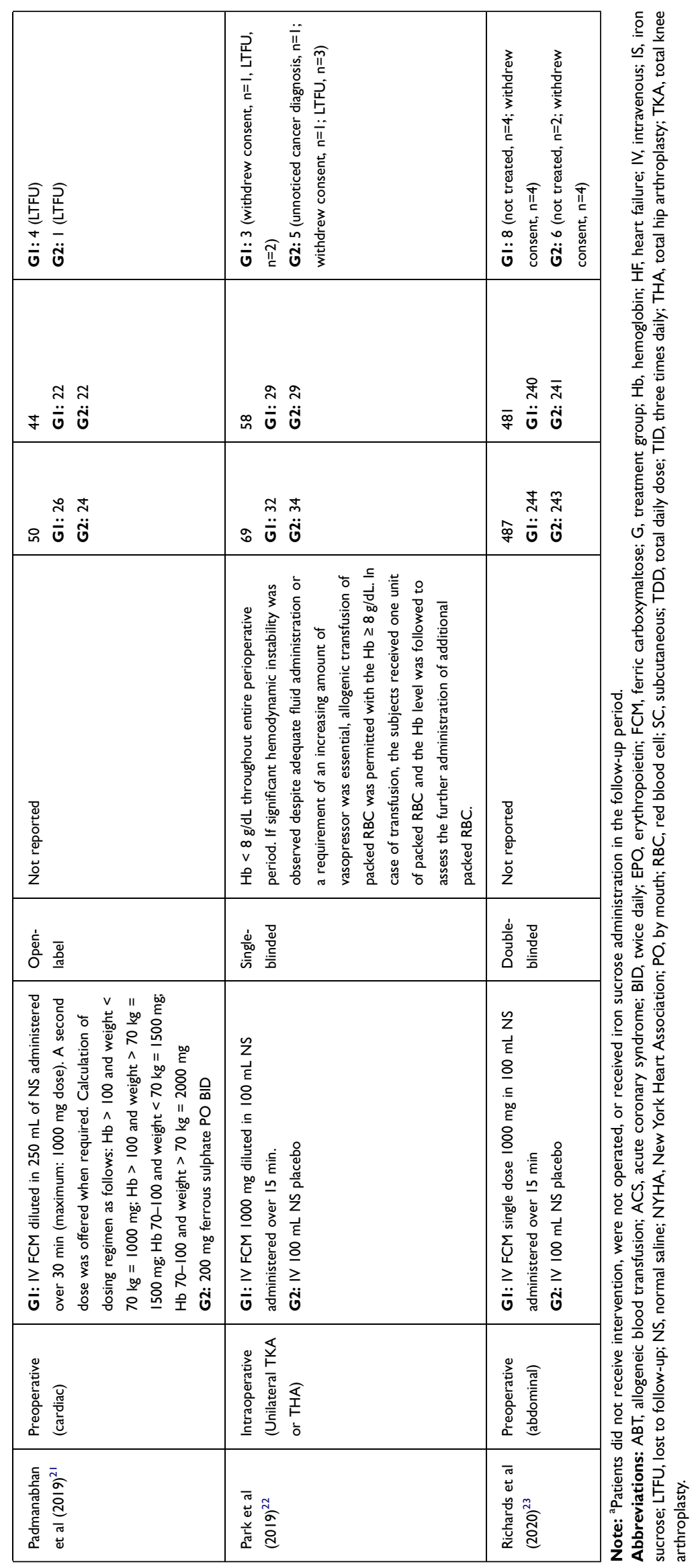


a robust PBM protocol including preoperative treatment with iron, SC EPO, or both 1 month before surgery, discretionary tranexamic acid during and after surgery, and antithrombotic treatment with SC bemiparin (a low-molecular-weight heparin not approved in the United States); additionally, shed blood exceeding $400 \mathrm{~mL}$ was automatically reinfused via an autotransfusion device. ${ }^{15}$ In the third study, patients in the usual care group received perioperative anemia management, which did not disallow prescription or administration of IV iron. ${ }^{17}$ Five of the 10 studies prespecified blood transfusion thresholds; 3 specified $\mathrm{Hb}$ $<7 \mathrm{~g} / \mathrm{dL},{ }^{7,15-17,19}$ and 1 of these set the number of RBC transfusions at $3 .^{16}$ Three of the 5 studies specified $\mathrm{Hb}<8$ $\mathrm{g} / \mathrm{dL}^{15,22}$ or $7.1-8.9 \mathrm{~g} / \mathrm{dL}$ in the presence of severe symptoms. ${ }^{16}$

\section{Study Populations}

Baseline characteristics of patients are provided in Table 2. Most of the study populations (9/10) had an average age of 60 years or older, and 9 of the 10 were generally evenly distributed with respect to age across treatment groups. The difference in age distribution between the FCM group and the comparator arm in the sixth study occurred by chance and was not explained by the authors. Eight studies had a greater percentage of women., ${ }^{75,16,19-22}$ Mean weight was lowest among patients undergoing surgery for menorrhagia ${ }^{20}$ and highest among those undergoing abdominal surgery. ${ }^{17}$ The American Society of Anesthesiologists (ASA) physical status (grades ranged from I [defined as normal and healthy] to VI [declared brain-dead, organs to be donated]) varied by surgical population in the intervention group; $27-58 \%$ of patients undergoing abdominal surgery, ${ }^{17,23} 45 \%$ undergoing colorectal cancer surgery, ${ }^{18}$ and $20 \%$ undergoing orthopedic surgery had ASA Grade III (presence of severe systemic disease) or greater. ${ }^{15,24}$ In each of the studies reporting baseline hematopoietic parameters, the patients met criteria for IDA (mean baseline $\mathrm{Hb}<11 \mathrm{~g} / \mathrm{dL}$, serum ferritin $<300 \mathrm{ng} / \mathrm{mL}$, and TSAT $<25 \%$ ).

\section{Risk of Bias Assessment}

Overall, the studies were considered to have a high risk of bias, largely with regard to the blinding of patients and personnel and blinding of outcome assessments (Figures 2 and 3).

\section{Random Sequence Generation}

Eight out of 10 studies were considered to have a low risk of bias for random sequence generation, as they clearly reported appropriate randomization Che techniques. ${ }^{15,17-21,23,25}$ However, the random sequence method using Excel in Khalafallah et $\mathrm{al}^{7}$ was questionable and not described in Park et al, ${ }^{22}$ making the risk of bias unclear.

\section{Allocation Concealment}

Eight out of 10 studies were rated as having low risk of bias for allocation concealment. ${ }^{7,15,17,19,22,23,25}$ The studies by Keeler et $\mathrm{al}^{18}$ and Lee et $\mathrm{al}^{20}$ did not adequately describe the concealment methods of treatment allocation by an independent unit; selection bias was thus deemed unclear in the risk of bias for allocation concealment.

\section{Blinding}

Five of the 10 studies had an open-label design, ${ }^{7,17,18,20,21}$ and 3 were patient-blinded only, ${ }^{15,19,22}$ leading to a high risk of performance bias; the remaining studies had a double-blind design, which were assigned a low risk of bias. ${ }^{16,23}$ Three studies had an unclear risk of detection bias; neither Keeler et $\mathrm{al}^{18}$ nor Kim et al ${ }^{19}$ clearly stated who performed the outcome assessments, and BernabeuWittel et $\mathrm{al}^{16}$ did not describe the study's blinding measures. Detection bias was low in Bisbe et $\mathrm{al}^{15}$ and Richards et $\mathrm{al}^{23}$ but was high in Froessler et al, Lee, Padmanabhan, and Park owing to a lack of description of outcome blinding measures in these open-label studies ${ }^{17,20-22}$ and in Khalafallah et al owing to the recording of adverse events (AEs) by personnel who administered the study drug. ${ }^{7}$

\section{Incomplete Outcome Data}

Risk of attrition bias was considered low in 3 studies, in Bernabeu-Wittel et al because losses to follow-up were disclosed and the attrition was reasonable and not expected to affect results, ${ }^{16}$ in Froessler et al because the rationale was given for study termination ${ }^{17}$ and Richards et al because attrition was described and accounted for in statistical analysis. ${ }^{23}$ Risk of attrition bias was deemed unclear for 6 studies because no explanations were offered for withdrawal for either treatment group, ${ }^{7}$ for the relevance of incomplete data sets available at the end of the study period, ${ }^{15,21,22}$ for the impact of incomplete adherence-which was assessed in 1 study-to allocated treatment, ${ }^{18}$ and for interpolation of missing data using linear regression analysis when the total sample size is very small. ${ }^{20}$ The risk of attrition bias was high for Kim et al, in which a modified intention-to-treat analysis was used. ${ }^{19}$ 


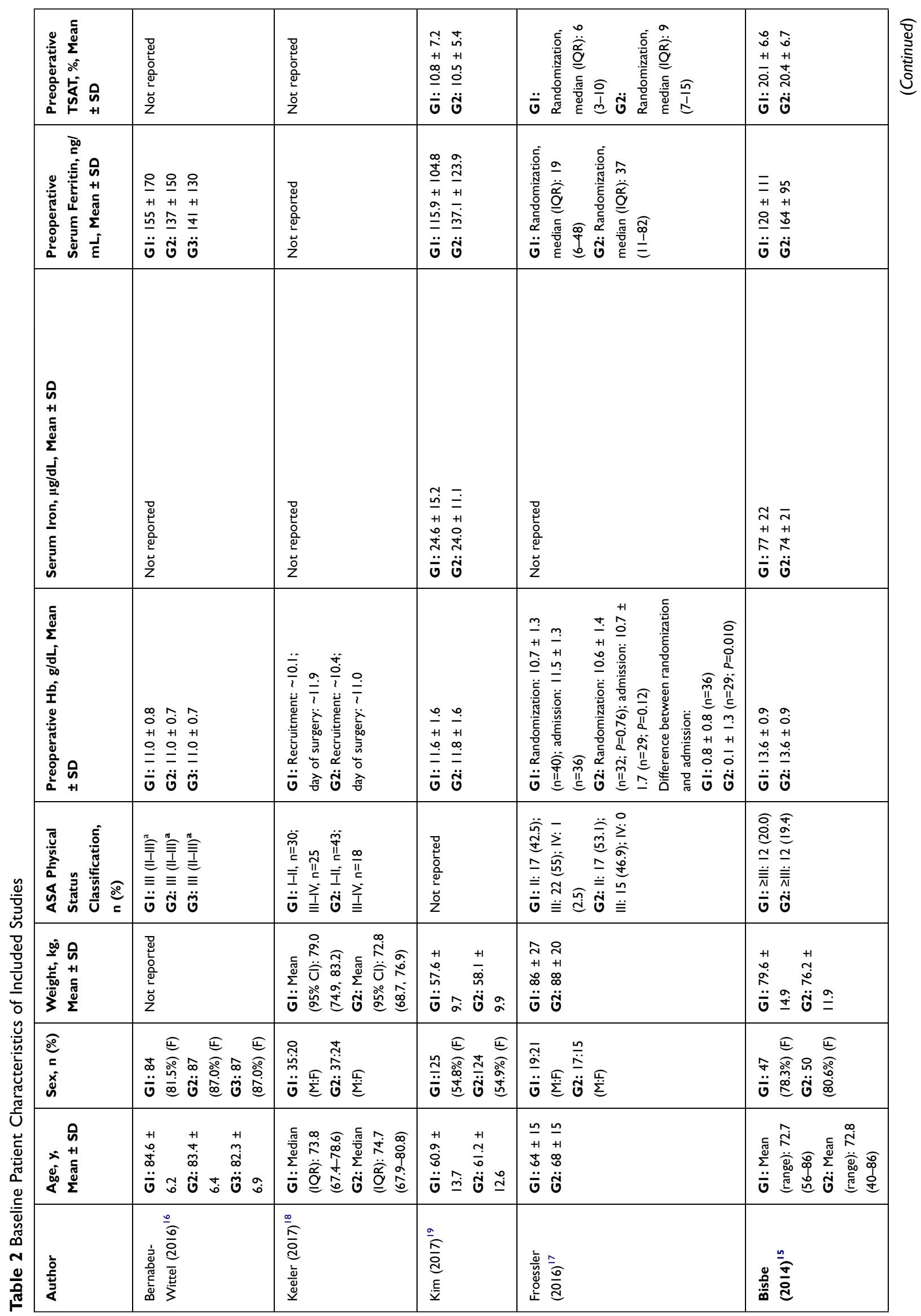




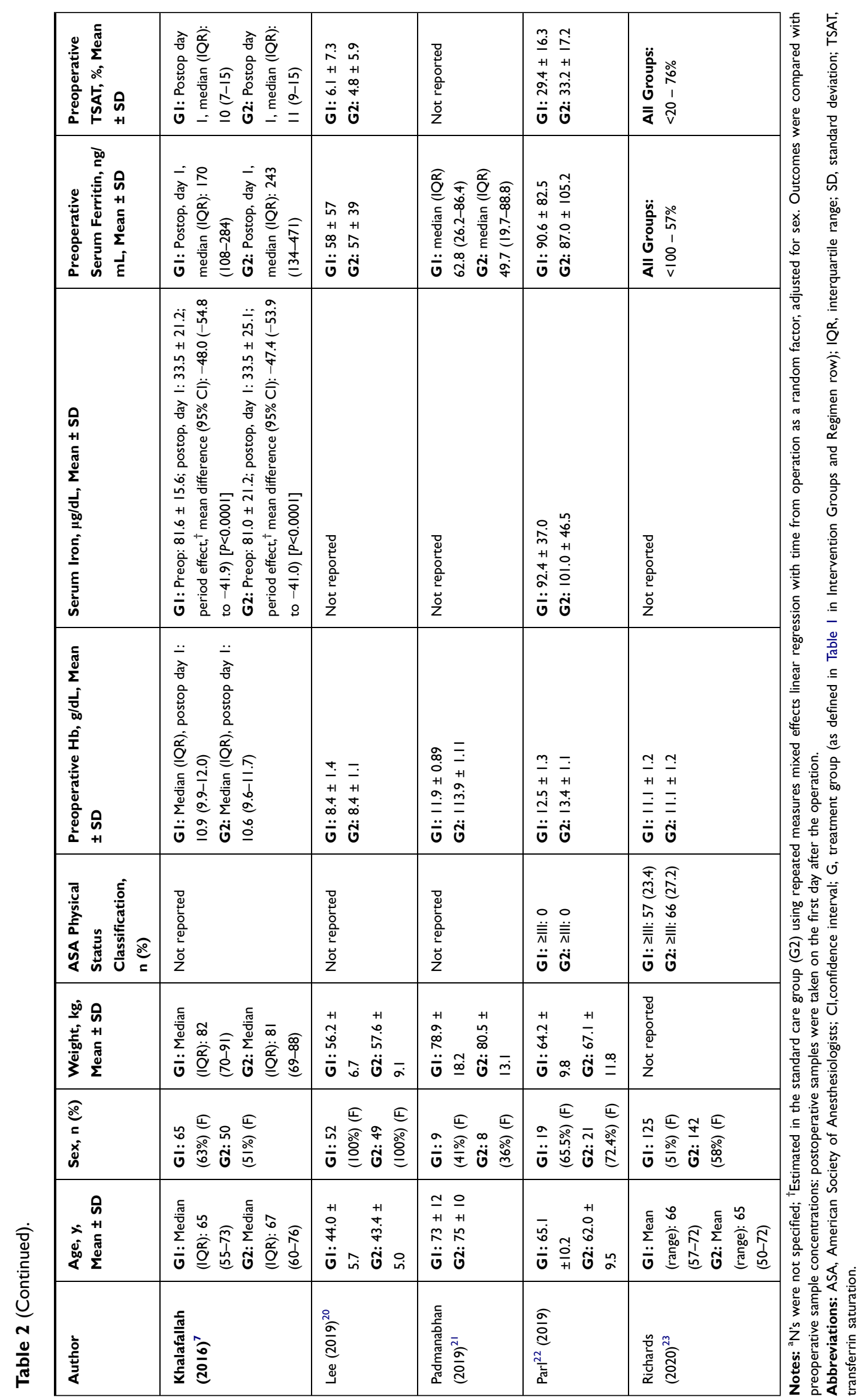




\begin{tabular}{|c|c|c|c|c|c|c|c|c|c|c|}
\hline & 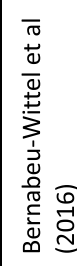 & 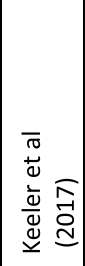 & 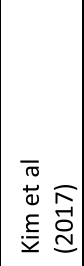 & 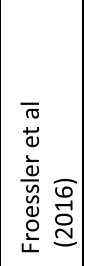 & 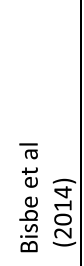 & 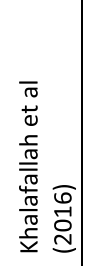 & 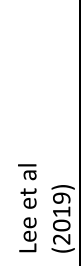 & 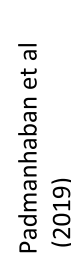 & 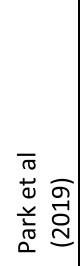 & 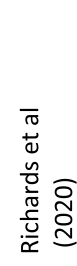 \\
\hline Random sequence generation & $\oplus$ & $\oplus$ & $\oplus$ & $\Theta$ & $\oplus$ & $\Theta$ & $\oplus$ & $\oplus$ & (อ) & $\oplus$ \\
\hline Allocation concealment & $\oplus$ & (2) & (2) & $\oplus$ & $\oplus$ & $\oplus$ & (2) & $\oplus$ & $\oplus$ & $\oplus$ \\
\hline Blinding of patients and personnel & $\oplus$ & $\Theta$ & $\Theta$ & $\Theta$ & $\Theta$ & (2) & $\Theta$ & $\Theta$ & $\Theta$ & $\oplus$ \\
\hline Blinding of outcome assessment & (2) & (อ) & $\Theta$ & $\Theta$ & $\oplus$ & $\Theta$ & $\Theta$ & $\Theta$ & $\Theta$ & $\oplus$ \\
\hline Incomplete outcome data & $\oplus$ & $\Theta$ & $\oplus$ & $\oplus$ & $\Theta$ & (2) & (2) & (2) & (2) & $\oplus$ \\
\hline Selective reporting & $\oplus$ & $\oplus$ & $\oplus$ & $\oplus$ & $\oplus$ & $\oplus$ & $\oplus$ & $\oplus$ & $\oplus$ & $\oplus$ \\
\hline Other Bias & $\oplus$ & (อ) & (อ) & (2) & (2) & $\oplus$ & $\Theta$ & $\Theta$ & $\Theta$ & $\oplus$ \\
\hline
\end{tabular}

Figure 2 Risk of bias summary: authors' judgment about risk of bias for each item for each of the 6 included studies. The symbol "+" indicates low risk of bias, "?" indicates unclear risk of bias, and "-" indicates high risk of bias.

Random sequence generation (selection bias)

Allocation concealment (selection bias)

Blinding of patients and personnel (performance bias)

Blinding of outcome assessment (detection bias)

Incomplete outcome data (attrition bias)

Selective reporting (reporting bias)

Other Bias

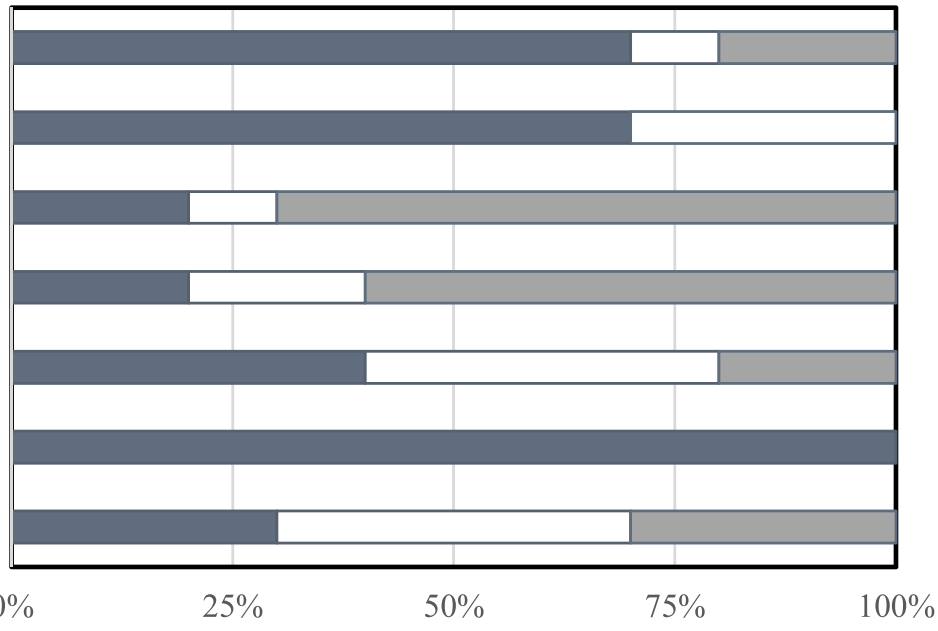

Low risk of bias $\quad \square$ Unclear risk of bias $\quad \square$ High risk of bias

Figure 3 Risk of bias: authors' judgment about risk of bias presented as percentages across all 6 included studies.

\section{Selective Reporting}

In Keeler et al, the treatment effects for secondary endpoints of serum ferritin and TSAT were not reported and reported outcomes, including postoperative length of hospital stay and 90-day mortality rates, were not prespecified, ${ }^{18}$ suggesting a high risk of reporting bias. For the other 9 included studies, all planned outcomes were reported.

\section{Other Potential Sources of Bias}

One of the 6 studies had a robust institution-specific patient blood management program in place that may have influenced outcome assessments. ${ }^{15}$ In 1 study, IV iron was not considered part of usual care at the time of study commencement, but was nonetheless not prohibited. ${ }^{17}$ A differential number of patients experiencing protocol deviations was noted in the study groups of 
1 study. ${ }^{18} \mathrm{Kim}$ et al elected to examine a binary primary outcome measure instead of a continuous outcome measure, which may have skewed response. ${ }^{19}$ Subjects in the Lee et al study who were assigned to iron sucrose returned to the study site for three dosing visits, whereas those assigned to FCM only had one visit, which may have skewed the results in favor of IS. ${ }^{20}$ A large portion of patients in the Padmanabhan et al study did not return to receive their second dose of $\mathrm{FCM}$, which may have skewed the results against IV iron. ${ }^{21}$ Lastly, the Park et al study was significantly underpowered for the primary outcomes selected resulting in potential high risk of bias. $^{22}$

\section{Outcomes}

All studies included reported absolute or relative change from baseline $\mathrm{Hb}$ concentrations. Change from baseline $\mathrm{Hb}$ concentration ranged from $1.3 \mathrm{~g} / \mathrm{dL}^{21}$ to $4.7 \mathrm{~g} / \mathrm{dL}^{23}$ among patients receiving preoperative FCM (including in the perioperative study) and $1.7 \mathrm{~g} / \mathrm{dL}^{15}$ to $3.2 \mathrm{~g} / \mathrm{dL}^{7}$ among those receiving postoperative FCM (Table 3). Six of the 10 studies $^{15,20,21,23}$ reported this outcome to be statistically significant versus comparators. ${ }^{7,16-19,22}$ A key outcome measure was change from baseline in iron stores; findings showed that preoperative FCM administration resulted in an increase in serum ferritin concentrations of $229 \mu \mathrm{g} / \mathrm{L}$ (vs $19 \mu \mathrm{g} / \mathrm{L}$ at baseline) $)^{17}$ to $558 \mu \mathrm{g} / \mathrm{L}$ (levels at randomization not reported $)^{18}$ and a $15 \%{ }^{17}$ to $35 \%{ }^{19}$ increase in TSAT. Postoperative administration resulted in a $114^{7}$ to $571 \mu \mathrm{g} / \mathrm{L}^{15}$ increase in serum ferritin concentration and $7.2 \%{ }^{15}$ to $20 \%{ }^{17}$ increase in TSAT. Both Bernabeu-Wittel et $\mathrm{al}^{16}$ and Lee et $\mathrm{al}^{20}$ did not report change from baseline TSAT.

A secondary efficacy outcome measure was proportion of patients who received perioperative ABT (Table 4). Two ${ }^{7,17}$ of the 10 studies found statistically significantly lower rates of ABT in patients receiving FCM versus comparators in the perioperative surgical settings (absolute difference: $18.75 \%)^{17}$ and postoperative (absolute difference: $4 \%)^{7}$ The highest proportion of FCM-treated patients who received an ABT was $51.5 \%(53 / 103)$ in Bernabeu-Wittel et al, compared with $52 \%(52 / 100)$ in the FCM plus EPO group and 54\% (54/100) in the placebo group $;^{16}$ in Khalafallah et al, $1 \%(1 / 103)$ of patients receiving FCM versus 5\% (5/98) receiving standard of care received an $\mathrm{ABT}^{7}$

Outcome measures included the proportion of patients who experienced AEs, postoperative mortality rate, and hospital length of stay (Table 4). The proportion of patients with AEs was 6.8\% (15/222) in the FCM group and $0.4 \%(1 / 223)$ in the placebo group in the study by Kim et al. ${ }^{19}$ Bisbe et al reported AEs in 33\% (20/60) of patients in the FCM group and $32 \%(20 / 62)$ in the ferrous glycine sulfate comparator group $(P=\mathrm{NS}) ;{ }^{15}$ this included all AEs reported during hospitalization (ie, before initiation of iron replacement therapy) and AEs related to surgical complications from initiation to 30 days postoperatively. ${ }^{15}$ Five percent of patients experienced AEs in the FCM group compared to $2 \%$ in the placebo group (risk ratio 2.20, 95\% CI 0.78-6.24). ${ }^{23}$ Zero AEs among treatment groups were reported in both Lee et $\mathrm{al}^{20}$ and Park et al. ${ }^{22}$ Postoperative mortality was reported in 6 of the 10 included studies and ranged from $1 \%(2 / 237)^{23}$ to $11.7 \%$ (12/103) among patients receiving FCM $^{16}$ compared with $0^{17,20,21}$ to $10 \%(10 / 100)$ receiving placebo. ${ }^{16}$ The deaths were not attributed to study drug in the 5 studies; 3 studies did not discuss the possibility of a relationship between the deaths and study drug, ${ }^{17,18,23} 1$ study stated that the single death was due to unrelated causes, ${ }^{21}$ and 1 study stated that the causes of death were similar among the 3 treatment groups (IV FCM, IV FCM in combination with EPO, and placebo). ${ }^{16}$

The length of hospital stay ranged from $6^{17,18}$ to 10.7 days ${ }^{19}$ with $\mathrm{FCM}$ versus $6{ }^{18}$ to 11.6 days $^{7}$ with comparators (Table 5). Two of the 8 studies reported statistically significant differences in transfusion rate ${ }^{7,17}$ and 2 studies reported significant differences in length of hospital stay between FCM and its comparators; the absolute difference in hospital stay was 3 days in Froessler et $\mathrm{al}^{17}$ and 2.8 days in Khalafallah et al. ${ }^{7}$ The variations in discharge criteria at the different institutions may have contributed to the differences in lengths of stay.

Validated measures of QOL included the Short Form Health Survey (SF-36 and SF-12) in 5 studies, ${ }^{7,16,17,20,21}$ the EuroQol 5-dimension quality of life scale (EQ-5D) in 3 studies, ${ }^{15,21,23}$ the Barthel Index questionnaires in 1 study, ${ }^{15}$ the Multidimensional Fatigue Inventory (MFI), ${ }^{23}$ and the European Organization for Research and Treatment of Cancer Quality of Life Questionnaire-Core 30 (EORTC QLQ-C30) questionnaire and the QLQ Gastric Cancer Module (QLQ-STO22) in 1 study. ${ }^{19}$ There were no statistically significant differences between IV FCM and comparators in QOL (overall score, change in score, or treatment effect) in any of these 7 studies. $^{7,15-17,19,21,23}$ Bisbe et al reported no significant differences between IV FCM and the comparator (ferrous 


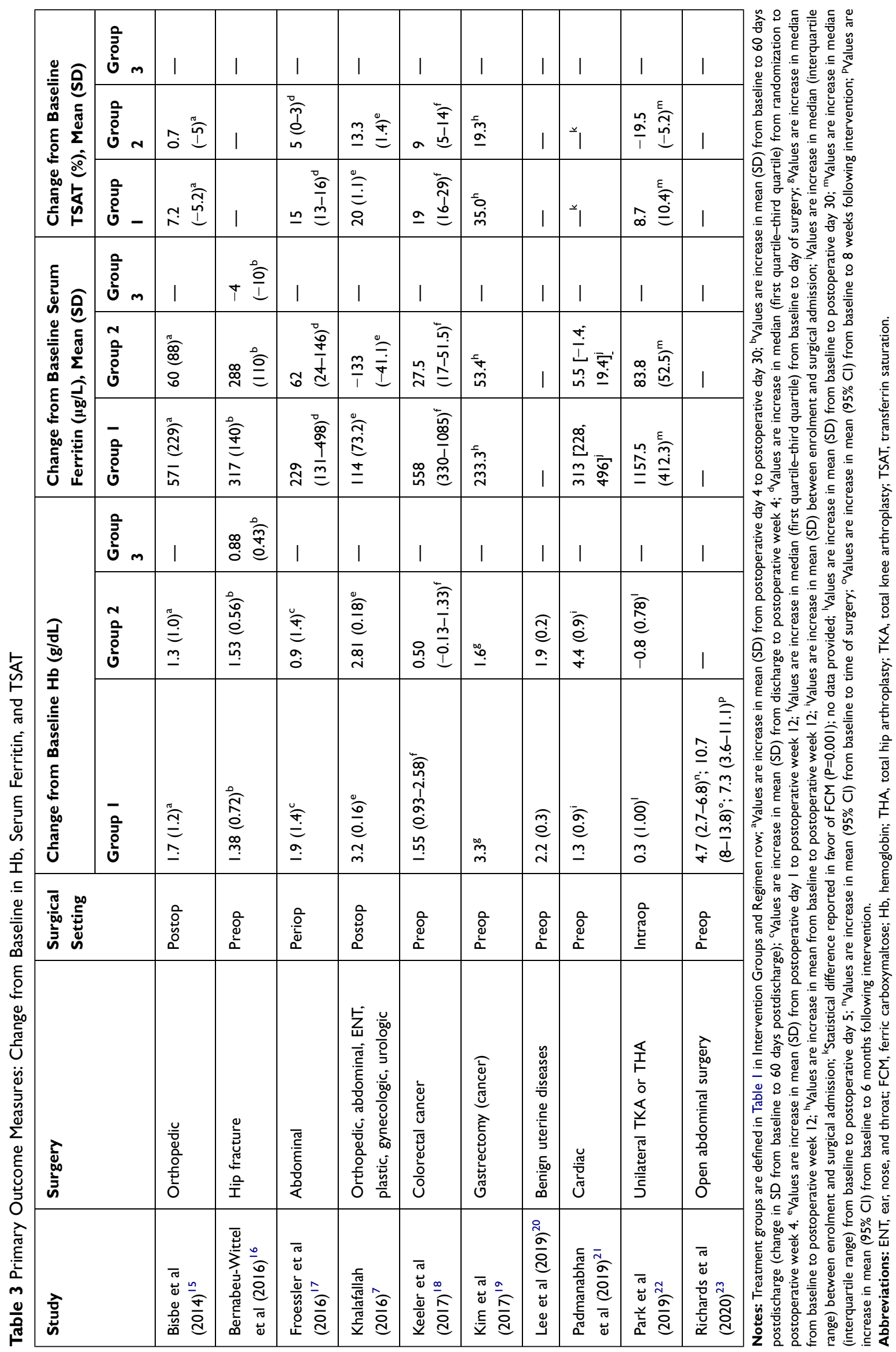




\begin{tabular}{|c|c|c|c|c|c|c|c|c|c|c|c|}
\hline \multirow{3}{*}{ 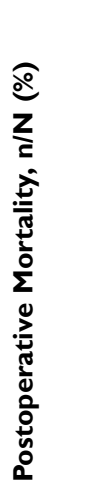 } & $\begin{array}{l}0 \\
0 \\
0 \\
\text { பे }\end{array}$ & 1 & $\stackrel{\circ}{\stackrel{\circ}{\circ}} \stackrel{\circ}{=}$ & 1 & 1 & 1 & 1 & 1 & 1 & 1 & 1 \\
\hline & $\begin{array}{l}0 \\
0 \\
0 \\
0\end{array}$ & 1 & 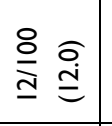 & 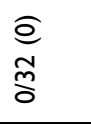 & 1 & $\bar{\sigma} \stackrel{\widehat{o}}{\dot{\sigma}}$ & 1 & $\frac{a}{d}$ & సิ & 1 & $\stackrel{\stackrel{\sim}{\Xi}}{\text { 의 }}$ \\
\hline & $\begin{array}{l}\overline{0} \\
\overline{0} \\
0 \\
0\end{array}$ & I & 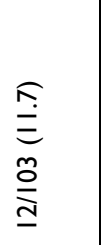 & 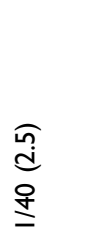 & I & 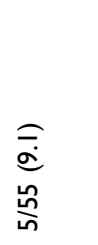 & 1 & กิ & 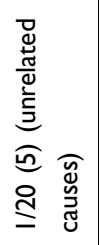 & I & 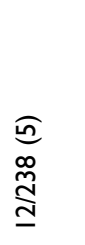 \\
\hline \multirow{3}{*}{ 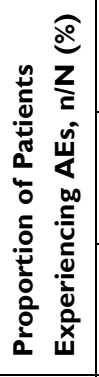 } & 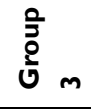 & I & 1 & 1 & I & I & 1 & I & I & 1 & I \\
\hline & $\begin{array}{l}0 \\
0 \\
0 \\
0\end{array}$ & 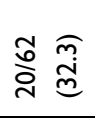 & I & I & 1 & 1 & $\stackrel{\widetilde{\Xi}}{\stackrel{\Im}{\Xi}}$ & $\frac{g}{\partial}$ & 요 & 1 & 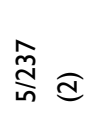 \\
\hline & $\begin{array}{l}0 \\
0 \\
0 \\
0\end{array}$ & 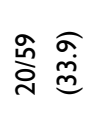 & I & I & | & I & 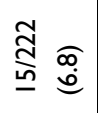 & กิ & 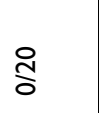 & ָิ & 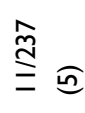 \\
\hline \multirow{3}{*}{ 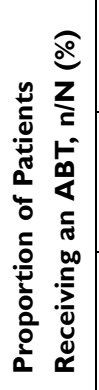 } & $\begin{array}{l}0 \\
\vdots \\
0 \\
0\end{array}$ & 1 & 总䍃 & 1 & 1 & I & 1 & 1 & 1 & 1 & 1 \\
\hline & $\begin{array}{l}0 \\
0 \\
0 \\
0\end{array}$ & 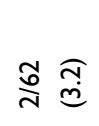 & 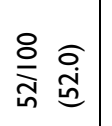 & $\stackrel{\tilde{m}}{\underline{m}} \frac{\widehat{m}}{m}$ & 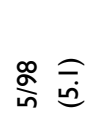 & $\bar{\Phi} \stackrel{\widehat{\alpha}}{\circ}$ & $\stackrel{\frac{\sigma}{\mathcal{J}}}{\stackrel{\alpha}{=}}$ & $\stackrel{g}{g}$ & 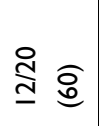 & $\stackrel{\widehat{\sigma}}{\stackrel{\widehat{\sigma}}{\mathcal{V}}}$ & 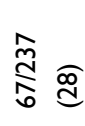 \\
\hline & _ & 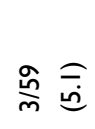 & 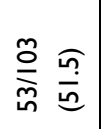 & 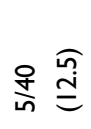 & $\stackrel{o}{=} \overline{\bar{e}}$ & 瓷 & $\stackrel{\infty}{\stackrel{\infty}{m}} \underset{f}{\stackrel{f}{=}}$ & กิ & 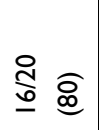 & 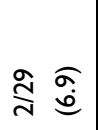 & 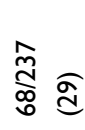 \\
\hline 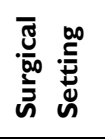 & & 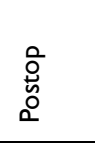 & $\begin{array}{l}\stackrel{0}{0} \\
\stackrel{0}{0} \\
\frac{2}{2}\end{array}$ & $\frac{\circ}{\frac{0}{\bar{v}}}$ & $\begin{array}{l}\text { o } \\
\text { ŏ } \\
\text { on }\end{array}$ & $\begin{array}{l}\stackrel{0}{0} \\
\frac{0}{2} \\
\frac{2}{2}\end{array}$ & 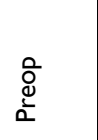 & 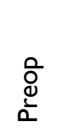 & 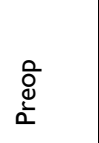 & 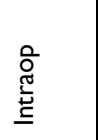 & 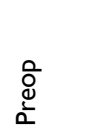 \\
\hline \multicolumn{2}{|l|}{ 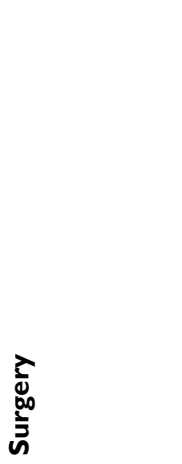 } & 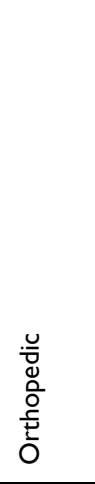 & 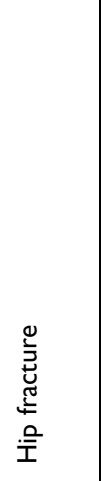 & 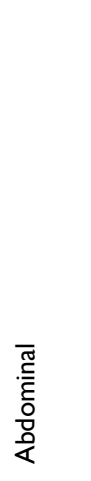 & 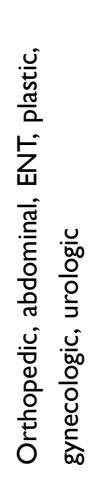 & 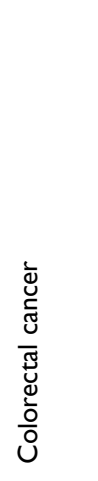 & 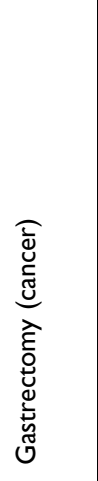 & 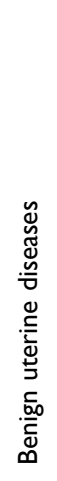 & 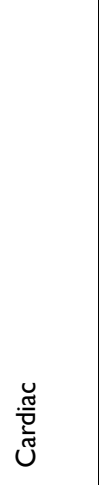 & 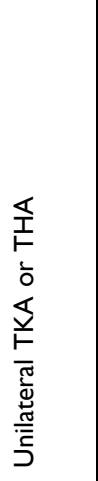 & 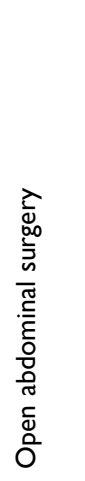 \\
\hline \multicolumn{2}{|l|}{ ते } & 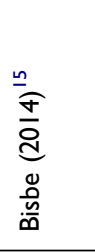 & 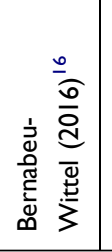 & 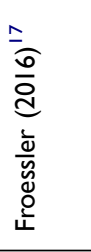 & 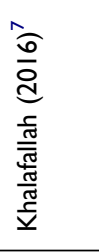 & 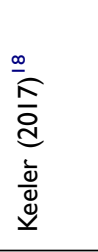 & 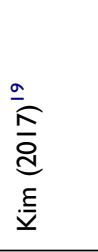 & 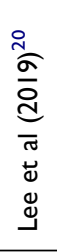 & 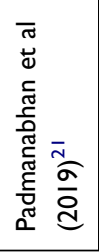 & 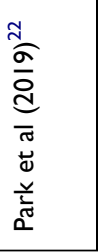 & 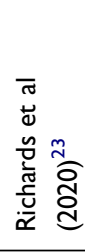 \\
\hline
\end{tabular}




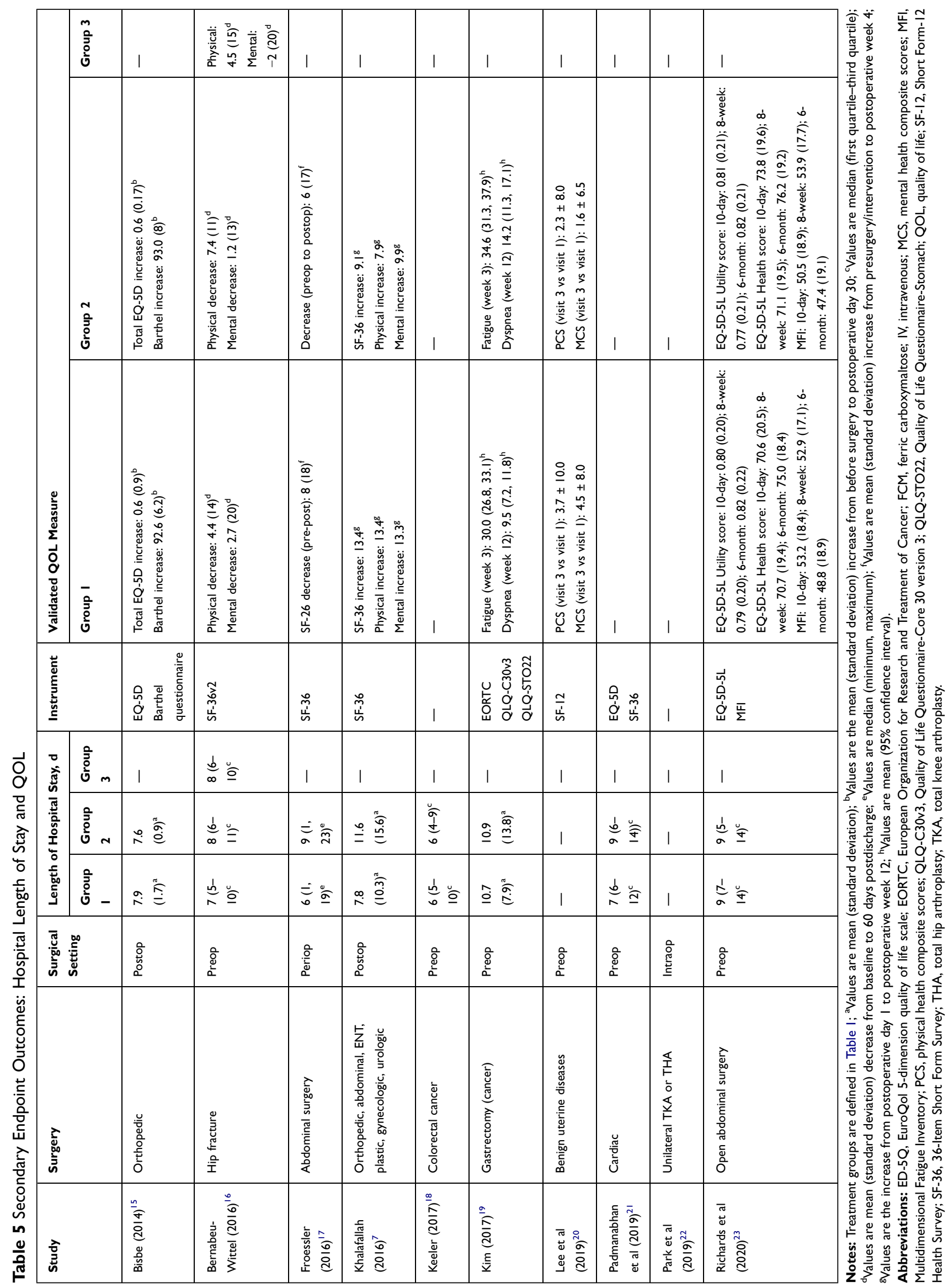


glycine sulfate) in total EQ-5D and Barthel scores. ${ }^{15}$ However, among patients with preoperative iron deficiency (serum ferritin $<100 \mathrm{ng} / \mathrm{mL}$ ), the IV FCM group had significantly better (ie, lower) mean \pm SD EQ-5D subscores than the comparator group for "usual activities" $(1.9 \pm 0.3$ vs $2.1 \pm 0.3 ; P=0.026)$ and "anxiety or depression" (1.3 [0.6] vs $1.6[0.7] ; P=0.074)$ at the end of the study. ${ }^{15}$ In addition, among patients with severe postoperative anemia $(\mathrm{Hb}<10.0 \mathrm{~g} / \mathrm{dL})$, the FCM group had significantly better scores for "usual activities" than the comparator group at the end of the study (1.9 vs 2.3 [SD not reported]; $P=0.04){ }^{15}$

\section{Overall Quality of Evidence}

The GRADE criteria were applied to rate the quality of evidence for all specified outcomes in this review (Supplementary Data, Appendix 2). Evidence quality was downgraded for risk of bias, inconsistency, indirectness, and imprecision. Across both primary and secondary endpoints, the overall quality of evidence was determined to be very low (Table 6). Publication bias was not detected. The rationale for these judgments are outlined in the Supplementary Data, Appendix 3.

\section{Discussion}

This SLR supports the use of FCM as treatment for adult patients with IDA in the preoperative and postoperative health states. In both the preoperative and postoperative elective surgery settings, IDA is a modifiable risk factor for elective surgical management. ${ }^{26,27}$ The 10 studies identified for inclusion in this SLR consistently reported change from baseline improvement in the three primary outcome measures: hemoglobin, ferritin, and TSAT. ${ }^{7,15-19}$ For these studies, there was less consistency for the association of FCM as treatment for perioperative IDA with each of the five secondary outcomes: ABT, adverse events, postoperative mortality, hospital length of stay, and QoL measures (see Tables 4 and 5).

Current guidelines from the Australian National Health and Medical Research Council ${ }^{29}$ and the United Kingdom National Institute for Health and Care Excellence ${ }^{30}$ recommend consideration of alternatives to blood transfusions for patients undergoing surgery and advise restrictive hemoglobin thresholds $(<7.0$ $\mathrm{g} / \mathrm{dL}$ ) for blood transfusions. In this SLR, three of the postoperative surgery studies reported either significantly fewer total ABT events ${ }^{17}$ or a significantly smaller proportion of patients receiving $\mathrm{ABT}^{7,19}$ with $\mathrm{FCM}$ than with the comparator. In the six preoperative surgery studies, the percentage of patients receiving ABT was not significantly different between assigned groups. $^{16,18-21,23}$ In one preoperative surgery study, FCM was associated with reduced hospital readmission for post-surgical complications. ${ }^{23}$ Nonetheless, additional studies will be needed to fully assess the association of perioperative IV iron repletion, averted ABT, and associated ABT complications. ${ }^{28,32}$ Adverse events during hospitalization were recorded in three studies; ${ }^{15,21,23}$ as either estimated blood loss, ${ }^{21}$ number of blood transfusions, ${ }^{23}$ or gastrointestinal AEs. ${ }^{21,33}$ Post-operative mortality rates varied across the studies and was lowest in the study of benign uterine surgery and highest in the study of hip fractures. ${ }^{16,20}$ Length of hospital stay and measures of QoL also varied across studies (Table 5). Advanced age, as well as multiple comorbidities may have played a role in the lack of significance between FCM and comparators in these studies. ${ }^{7}$

While all 10 studies were randomized controlled trials, clinical and methodological heterogeneity was evident across the studies (Table 1), along with variation in the design elements (eg, type of blinding, duration of followup, timing of preoperative and postoperative assessments, comparator used, dosage, treatment schedule), All of these factors are important considerations when evaluating the utility of the exposure for the reported primary and secondary outcomes. A meta-analysis was not deemed feasible for this SLR, given the heterogeneity across the studies. Nonetheless, our findings are consistent with two prior quantitative syntheses of IV iron repletion in surgical patients which reported the efficacy of FCM associated with postoperative hemoglobin in elective surgeries. ${ }^{34,36}$ Additionally, for this SLR we conducted a thorough systematic qualitative assessment, which permitted a quality of evidence GRADE assessment (Table 6) for each of the primary and secondary outcomes. Although the overall quality of evidence scores were very low, future SLRs with GRADE assessments and consensus guideline considerations will likely benefit from assessment of iron repletion for elective surgeries partitioned as preoperative versus postoperative interventions. Together, the totality of data from these studies support the beneficial effect of FCM for hematological parameters in elective surgery, while continuing to inform on the role of iron repletion in perioperative patient management. ${ }^{31}$ 


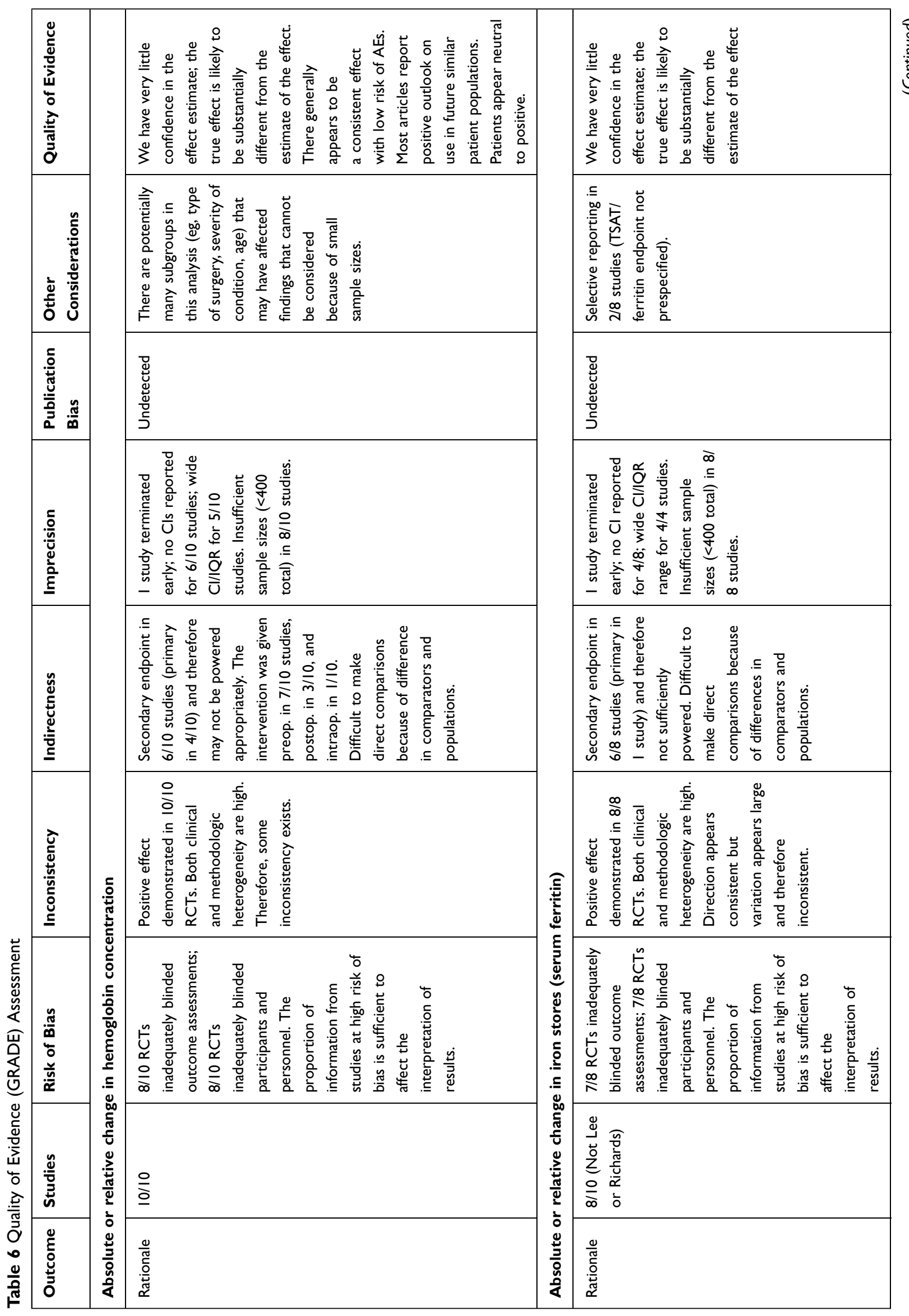




\begin{tabular}{|c|c|c|c|c|}
\hline 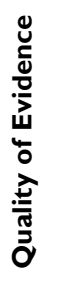 & & 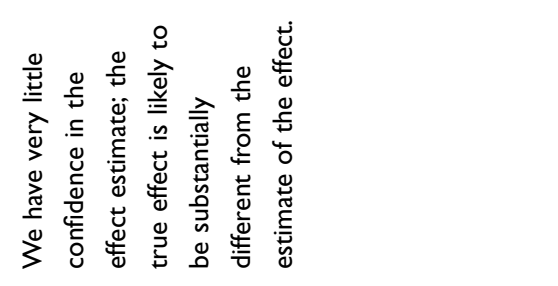 & & 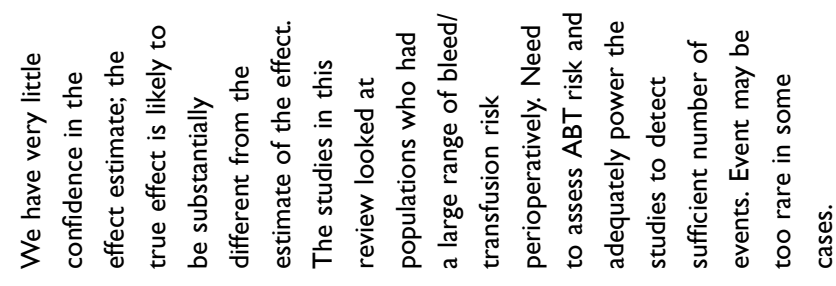 \\
\hline 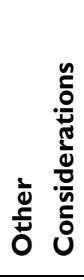 & & 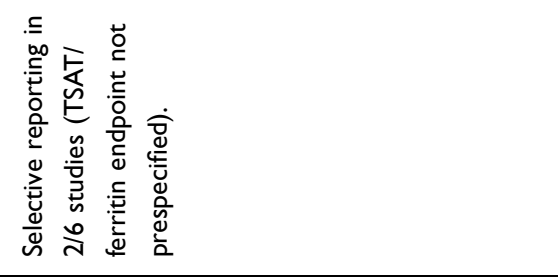 & & $\overleftarrow{\mathbf{z}}$ \\
\hline 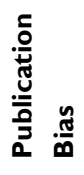 & & 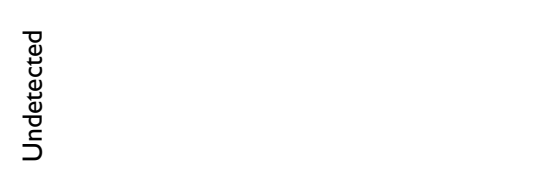 & & 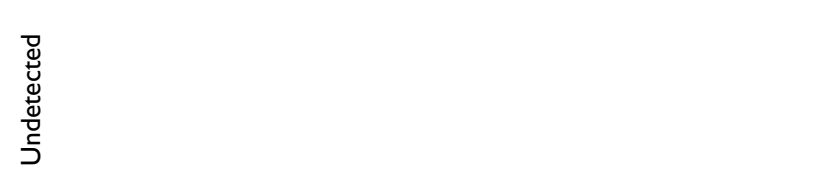 \\
\hline 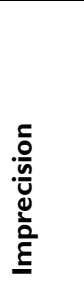 & & 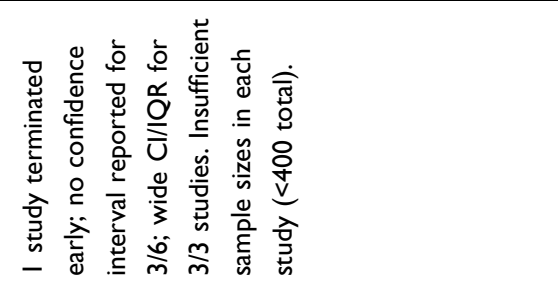 & & 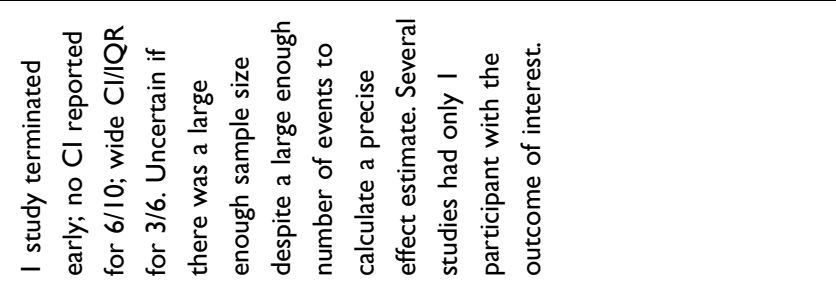 \\
\hline 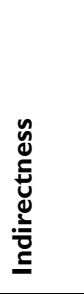 & & 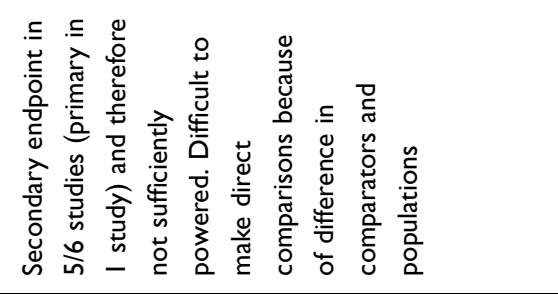 & & 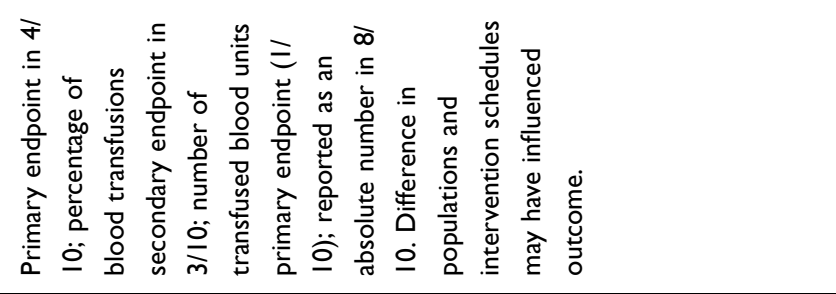 \\
\hline 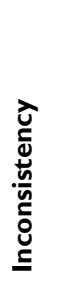 & & 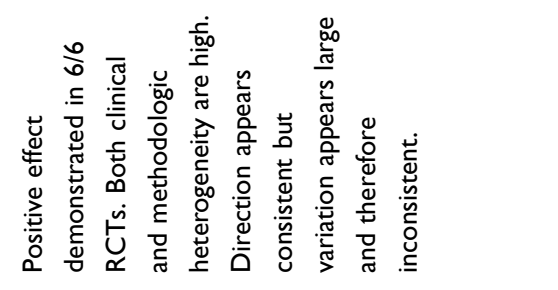 & 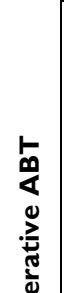 & 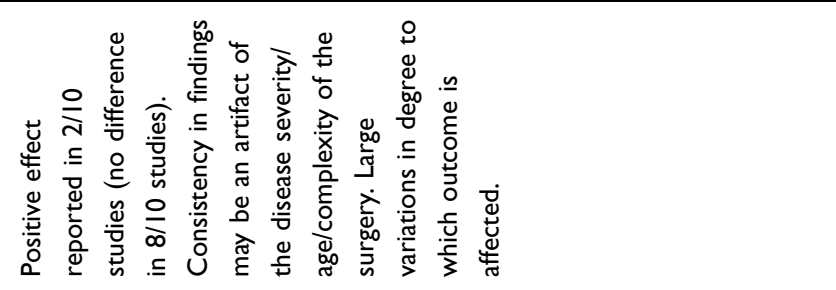 \\
\hline 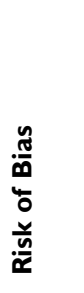 & 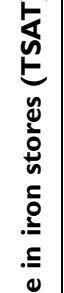 & 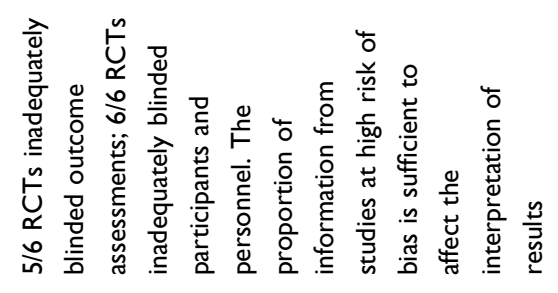 & 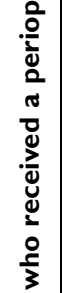 & 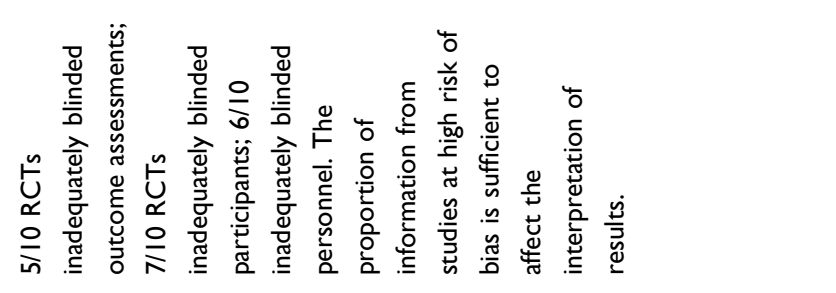 \\
\hline 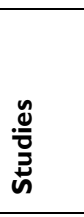 & 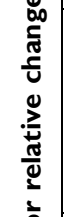 & 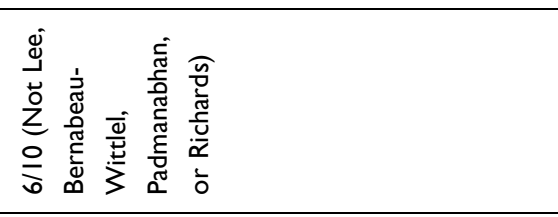 & 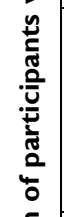 & 응 \\
\hline 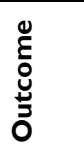 & 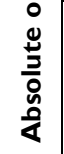 & 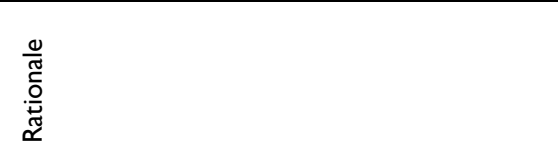 & 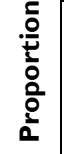 & $\begin{array}{l}\frac{0}{\tilde{g}} \\
\stackrel{0}{0} \\
\stackrel{0}{\tilde{g}}\end{array}$ \\
\hline
\end{tabular}




\begin{tabular}{|c|c|c|c|}
\hline & 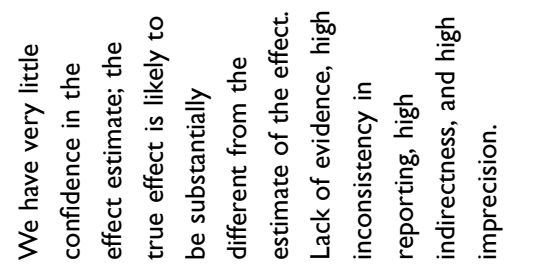 & & 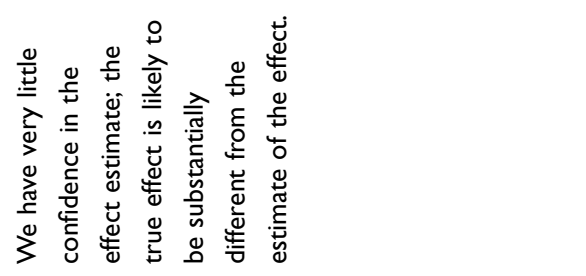 \\
\hline & $\overleftarrow{z}$ & & $\overleftarrow{z}$ \\
\hline & 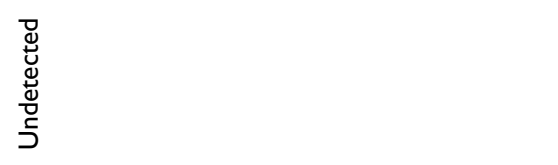 & & \\
\hline & 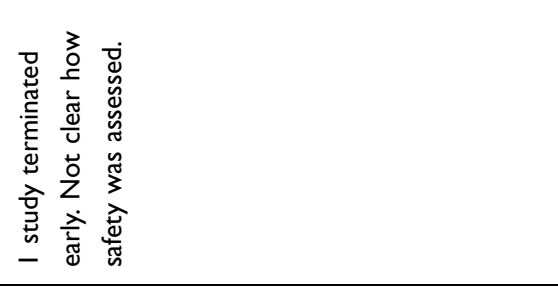 & & 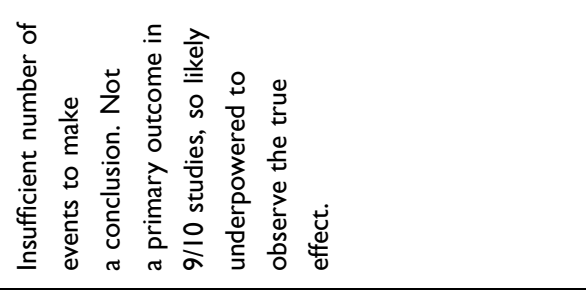 \\
\hline & 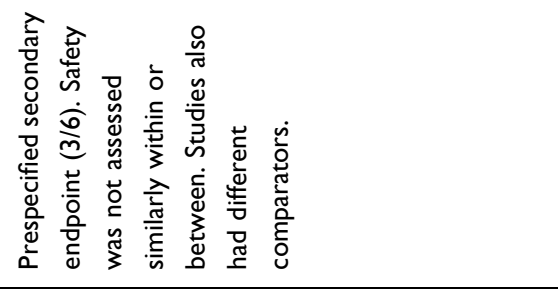 & & 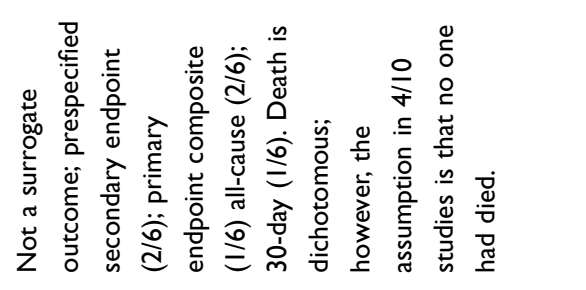 \\
\hline 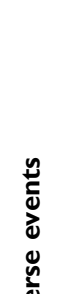 & 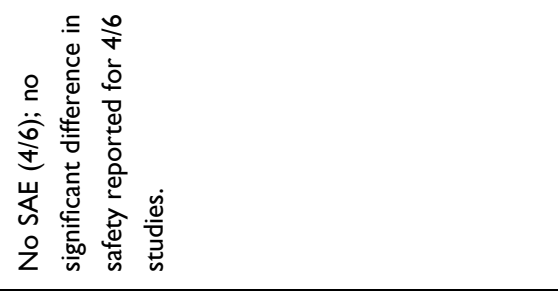 & & 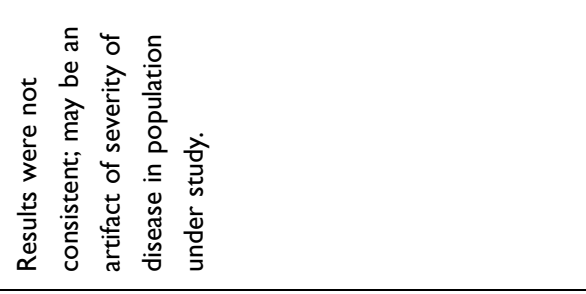 \\
\hline 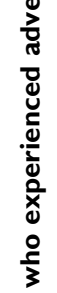 & 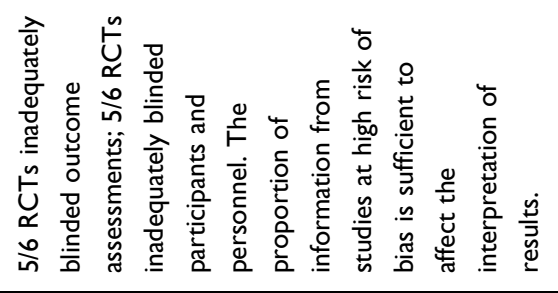 & & 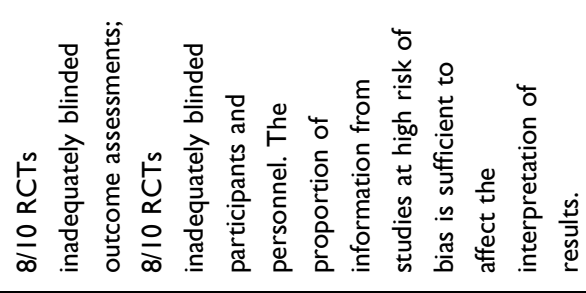 \\
\hline 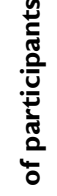 & 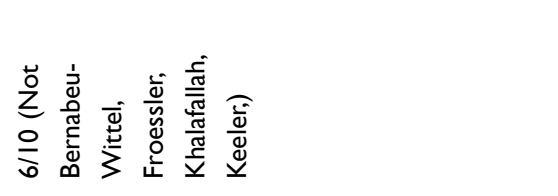 & 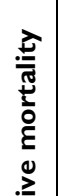 & 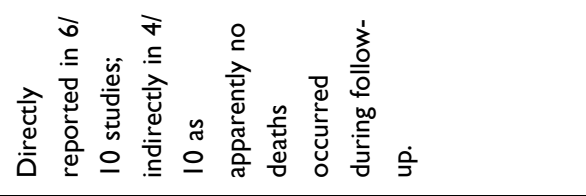 \\
\hline 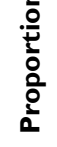 & 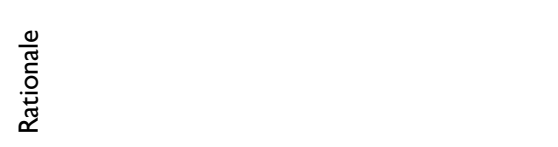 & 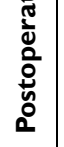 & 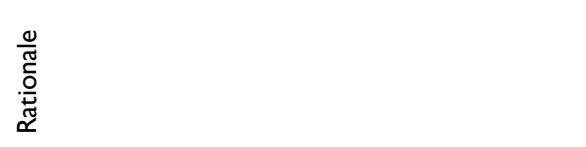 \\
\hline
\end{tabular}




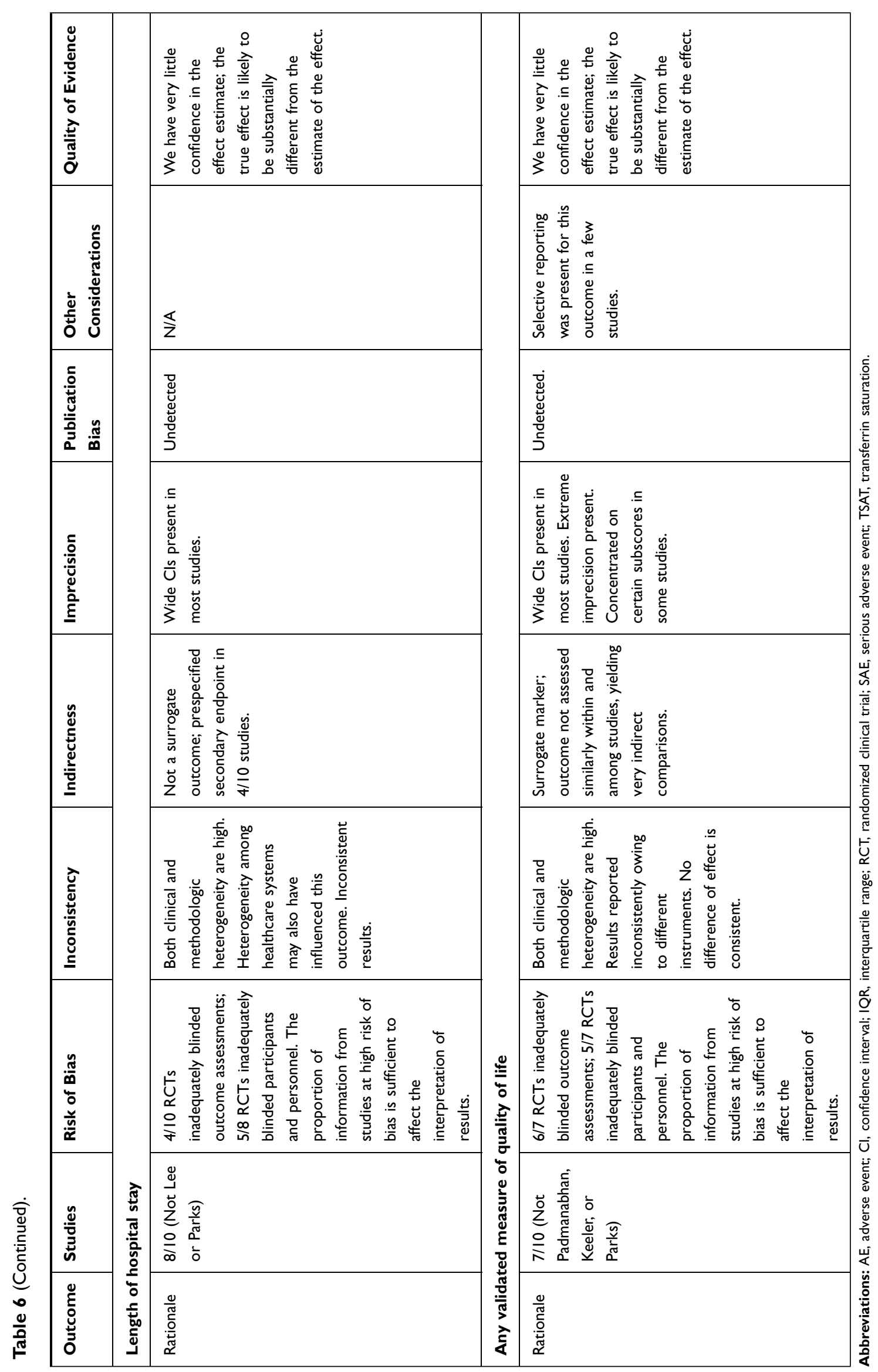




\section{Limitations}

Several methodologic limitations in this systematic review are noteworthy. Physicians were not blinded in 5 studies (4 open-label ${ }^{7,18,20,21}$ and 1 patient-blinded ${ }^{19}$ ). In 3 other studies, the physician was blinded to treatment allocation, but the comparators used in those studies (eg, oral iron ${ }^{15}$ or usual care consisting of no treatment, oral iron recommendation, and transfusion ${ }^{17,22}$ ) might allow the physician to distinguish which patients were assigned to receive IV FCM vs the comparator in others. Overall, the risks of performance and biases were high or uncertain, highlighting the need for more effective blinding of patients and study personnel involved in the administration of study drug or outcome assessments. Blinding in some studies may not be feasible, despite the impact of blinding on the measurement of study outcomes. For example, a difference in route of administration between treatment arms, ethical considerations (possibility of exposing study patients to risks when blinding with placebo), or logistical hurdles (eg, limited economic support or authorization to use or access appropriate placebos and masking procedures) may be challenging in independent investigator-initiated studies. ${ }^{7,35}$

Other limitations of study heterogeneity may limit generalizability of the findings resulting from differing thresholds of $\mathrm{Hb}$ level, inclusion criteria, baseline clinical characteristics (eg, Hb, serum iron, serum ferritin, TSAT, ASA classification), IV FCM dosing and timing of administration, $\mathrm{Hb}$ thresholds for intervention (IV iron and transfusion). Heterogeneity or absence of reporting of secondary outcomes such as duration of follow-up, differences in criteria for hospital discharge (which would affect length of stay and may explain differences observed between the studies), and QOL instrument used (SF$36,{ }^{7,16}$ EQ-5D and Barthel questionnaire, ${ }^{15}$ and EORTC QLQ-C30 and QLQ-STO22 ${ }^{19}$ ) did not allow for a more indepth review. Bias assessments in this review were qualitative, and meta-analysis was not feasible.

\section{Conclusion}

The preoperative correction of anemia and other hematological parameters with IV FCM appears to be a viable intervention to mitigate known risks associated with postsurgical anemia and consequent events such as the need for transfusion. ${ }^{36}$ Postoperative patients with IDA, in whom oral iron is contra-indicated who are not able to tolerate oral iron or achieve a satisfactory response to oral iron may also benefit from FCM administration. ${ }^{7,28}$ The benefits of IV iron suggested by this SLR support the recommendations of guidelines that incorporate the use of IV iron in patients undergoing elective surgery.

\section{Abbreviations}

ABT, allogeneic blood transfusion; AE, adverse event; ASA, American Society of Anesthesiologists; ENT, ear, nose, and throat; EORTC-QLQ-C30, the European Organization for Research and Treatment of Cancer Quality of Life Questionnaire-Core 30; EPO, erythropoietin; EQ-5D, EuroQol 5-dimension quality of life scale; FCM, ferric carboxymaltose; GRADE, Grading of Recommendations Assessment, Development, and Evaluation; $\mathrm{Hb}$, hemoglobin; IDA, iron-deficiency anemia; IV, intravenous; NHMRC, National Health and Medical Research Council; NICE, National Institute for Health and Care Excellence; NS, not significant; PBM, perioperative blood management; PRISMA, Preferred Reporting Items for Systematic Reviews and Meta-Analyses; QLQ-ST022, Quality of Life Questionnaire-Gastric Cancer Module; QOL, quality of life; $\mathrm{RBC}$, red blood cell; SC, subcutaneous; SD, standard deviation; SLR, systematic literature review; TSAT, transferrin saturation.

\section{Acknowledgments}

We would like to thank Jaclyn Vialet, BS, MLS, Director of the Health Education Resource Center at St. John's University College of Pharmacy and Health Sciences for her peer review and assessment of the electronic search strategies.

\section{Author Contributions}

JJJ, LMM, NB, MS: Main contribution to the study concepts and study design as well as supervision and revision of the manuscript.

JJJ, MS, LMM: Main contribution to the data acquisition, analysis, and interpretation.

JJJ and LMM: Main contribution to manuscript preparation.

NB: Main contribution to statistical support.

All authors made substantial contributions to conception and design, acquisition of data, or analysis and interpretation of data; took part in drafting the article or revising it critically for important intellectual content; agreed to submit to the current journal; gave final approval of the version to be published; and agree to be accountable for all aspects of the work. 


\section{Funding}

Editorial support for the preparation of this article was provided by Peloton Advantage, LLC (Parsippany, NJ, USA), an OPEN Health company, funded by American Regent, Inc. (Shirley, NY, USA), a wholly owned subsidiary of Daiichi Sankyo.

\section{Disclosure}

John Jeffrey Jones was a postdoctoral fellow employed by St. John's University (Jamaica, NY, USA) through a grant funded by American Regent, Inc. John Jeffrey Jones is currently employed by AVROBIO, Inc.; AVROBIO, Inc. was not involved in the content of this research or manuscript preparation. Linda M. Mundy, Nicole Blackman, and Michelle Shwarz are employees of American Regent, Inc., a wholly owned subsidiary of Daiichi Sankyo.

\section{References}

1. Spahn DR. Anemia and patient blood management in hip and knee surgery: a systematic review of the literature. Anesthesiology. 2010;113(2):482-495. doi:10.1097/ALN.0b013e3181e08e97

2. Beattie WS, Karkouti K, Wijeysundera DN, Tait G. Risk associated with preoperative anemia in noncardiac surgery: a single-center cohort study. Anesthesiology. 2009;110(3):574-581. doi:10.1097/ ALN.0b013e31819878d3

3. Foss NB, Kristensen MT, Kehlet H. Anaemia impedes functional mobility after hip fracture surgery. Age Ageing. 2008;37 (2):173-178. doi:10.1093/ageing/afm161

4. Napolitano LM. Perioperative anemia. Surg Clin North Am. 2005;85 (6):1215-1227. doi:10.1016/j.suc.2005.10.012

5. Avgerinos DV, Llaguna OH, Seigerman M, Lefkowitz AJ, Leitman IM. Incidence and risk factors for the development of anemia following gastric bypass surgery. World $J$ Gastroenterol. 2010;16(15):1867-1870. doi:10.3748/wjg.v16.i15.1867

6. Theusinger OM, Leyvraz PF, Schanz U, Seifert B, Spahn DR. Treatment of iron deficiency anemia in orthopedic surgery with intravenous iron: efficacy and limits: a prospective study. Anesthesiology. 2007;107(6):923-927. doi:10.1097/01. anes.0000291441.10704.82

7. Khalafallah AA, Yan C, Al-Badri R, et al. Intravenous ferric carboxymaltose versus standard care in the management of postoperative anaemia: a prospective, open-label, randomised controlled trial. Lancet Haematol. 2016;3(9):e415-425. doi:10.1016/S2352-3026(16)30078-3

8. Munoz M, Gomez-Ramirez S, Campos A, Ruiz J, Liumbruno GM. Pre-operative anaemia: prevalence, consequences and approaches to management. Blood Transfus. 2015;13(3):370-379. doi:10.2450/ 2015.0014-15

9. Hofmann A, Ozawa S, Farrugia A, Farmer SL, Shander A. Economic considerations on transfusion medicine and patient blood management. Best Pract Res Clin Anaesthesiol. 2013;27(1):59-68. doi:10.1016/j.bpa.2013.02.001

10. Camaschella C. Iron-deficiency anemia. N Engl J Med. 2015;372 (19):1832-1843. doi:10.1056/NEJMra1401038

11. Shander A, Knight K, Thurer R, Adamson J, Spence R. Prevalence and outcomes of anemia in surgery: a systematic review of the literature. Am J Med. 2004;116(Suppl 7A):58s-69s. doi:10.1016/j. amjmed.2003.12.013
12. Moher D, Liberati A, Tetzlaff J, Altman DG. Preferred reporting items for systematic reviews and meta-analyses: the PRISMA statement. PLoS Med. 2009;6(7):e1000097. doi:10.1371/journal. pmed.1000097

13. Higgins JP, Altman DG, Gotzsche PC, et al. The Cochrane Collaboration's tool for assessing risk of bias in randomised trials. BMJ. 2011;343:d5928. doi:10.1136/bmj.d5928

14. Balshem H, Helfand M, Schunemann HJ, et al. GRADE guidelines: 3. Rating the quality of evidence. J Clin Epidemiol. 2011;64 (4):401-406. doi:10.1016/j.jclinepi.2010.07.015

15. Bisbe E, Molto L, Arroyo R, Muniesa JM, Tejero M. Randomized trial comparing ferric carboxymaltose vs oral ferrous glycine sulphate for postoperative anaemia after total knee arthroplasty. $\mathrm{Br} J$ Anaesth. 2014;113(3):402-409. doi:10.1093/bja/aeu092

16. Bernabeu-Wittel M, Romero M, Ollero-Baturone M, et al. Ferric carboxymaltose with or without erythropoietin in anemic patients with hip fracture: a randomized clinical trial. Transfusion. 2016;56 (9):2199-2211. doi:10.1111/trf.13624

17. Froessler B, Palm P, Weber I, Hodyl NA, Singh R, Murphy EM. The important role for intravenous iron in perioperative patient blood management in major abdominal surgery: a randomized controlled trial. Ann Surg. 2016;264(1):41-46. doi:10.1097/SLA.0000000 000001646

18. Keeler BD, Simpson JA, Ng O, Padmanabhan H, Brookes MJ, Acheson AG. Randomized clinical trial of preoperative oral versus intravenous iron in anaemic patients with colorectal cancer. $\mathrm{Br}$ J Surg. 2017;104(3):214-221. doi:10.1002/bjs.10328

19. Kim YW, Bae JM, Park YK, et al. Effect of intravenous ferric carboxymaltose on hemoglobin response among patients with acute isovolemic anemia following gastrectomy: the FAIRY randomized clinical trial. JAMA. 2017;317(20):2097-2104. doi:10.1001/ jama.2017.5703

20. Lee S, Ryu KJ, Lee ES, Lee KH, Lee JJ, Kim T. Comparative efficacy and safety of intravenous ferric carboxymaltose and iron sucrose for the treatment of preoperative anemia in patients with menorrhagia: an open-label, multicenter, randomized study. $J$ Obstet Gynaecol Res. 2019;45(4):858-864. doi:10.1111/jog.13893

21. Padmanabhan H, Siau K, Nevill AM, et al. Intravenous iron does not effectively correct preoperative anaemia in cardiac surgery: a pilot randomized controlled trial. Interact Cardiovasc Thorac Surg. 2019;28(3):447-454. doi:10.1093/icvts/ivy226

22. Park HS, Kim TY, Kim HJ, Ro YJ, Jang HY, Koh WU. The effect of intraoperative ferric carboxymaltose in joint arthroplasty patients: a randomized trial. J Clin Med. 2019;8(10):1674. doi:10.3390/ jcm8101674

23. Richards T, Baikady RR, Clevenger B, et al. Preoperative intravenous iron to treat anaemia before major abdominal surgery (PREVENTT): a randomised, double-blind, controlled trial [published online ahead of print, 2020 Sep 4]. Lancet. 2020;396(10259):1353-1361. doi:10.1016/S0140-6736(20)31539-7

24. American Society of Anaesthesiologists House of Delegates/ Executive Committee. ASA physical status classification system. 2014. Available from: https://www.asahq.org/standards-and-guide lines/asa-physical-status-classification-system. Accessed August 12, 2019.

25. Bernabeu-Wittel M, Aparicio R, Romero M, et al. Ferric carboxymaltose with or without erythropoietin for the prevention of red-cell transfusions in the perioperative period of osteoporotic hip fractures: a randomized contolled trial. The PAHFRAC-01 project. BMC Musculoskelet Disord. 2012;13:27. doi:10.1186/1471-2474-13-27

26. Clevenger B, Richards T. Pre-operative anaemia. Anaesthesia. 2015;70(Suppl 1):20-28. doi:10.1111/anae.12918

27. Auerbach M. Intravenous iron in the perioperative setting [letter]. Am J Hematol. 2014;89(9):933. doi:10.1002/ajh.23793 
28. Munoz M, Auerbach M. Postoperative intravenous iron: a simple strategy to improve outcomes. Lancet Haematol. 2016;3(9):e401402. doi:10.1016/S2352-3026(16)30083-7

29. National Blood Authority. Patient Blood Management Guidelines: Module 2 Perioperative. Canberra, Australia: National Blood Authority; 2012.

30. Padhi S, Kemmis-Betty S, Rajesh S, Hill J, Murphy MF. Blood transfusion: summary of NICE guidance. BMJ. 2015;351:h5832. doi:10.1136/bmj.h5832

31. Thakrar SV, Clevenger B, Mallett S. Patient blood management and perioperative anaemia. BJA Educ. 2017;17(1):28-34. doi:10.1093/ bjaed/mkw061

32. Maxwell MJ, Wilson MJA. Complications of blood transfusion. Continuing Educ Anaesth Crit Care Pain. 2006;6(6):225-229. doi:10.1093/bjaceaccp/mk1053

33. Tolkien Z, Stecher L, Mander AP, Pereira DI, Powell JJ. Ferrous sulfate supplementation causes significant gastrointestinal side-effects in adults: a systematic review and meta-analysis. PLoS One. 2015;10(2):e0117383. doi:10.1371/journal.pone.0117383
34. Koo CH, Shin HJ, Cho H, Ryu JH. The effect of perioperative intravenous iron on hemoglobin in surgical patients: a meta-analysis. J Surg Res. 2020;246:42-51. doi:10.1016/j. jss.2019.08.023

35. Laso-Morales MJ, Vives R, Vallejo-Tarrat A, Calo N, ValleBeltran A, Pontes C. Single dose of intravenous ferric carboxymaltose infusion versus multiple fractionated doses of intravenous iron sucrose in the treatment of postoperative anaemia in colorectal cancer patients: study protocol for a randomised controlled trial. Trials. 2019;20(1):23. doi:10.1186/s13063-018-3125-2

36. Muñoz M, Gomez-Ramirez S, Cuenca J, et al. Very-short-term perioperative intravenous iron administration and postoperative outcome in major orthopedic surgery: a pooled analysis of observational data from 2547 patients. Transfusion. 2014;54(2):289-299. doi:10.1111/ trf. 12195

37. Page MJ, Moher D, Bossuyt PM, et al. PRISMA 2020 explanation and elaboration: updated guidance and exemplars for reporting systematic reviews. BMJ. 2021;372:n160. doi:10.1136/bmj.n71
Journal of Blood Medicine

\section{Publish your work in this journal}

The Journal of Blood Medicine is an international, peer-reviewed, open access, online journal publishing laboratory, experimental and clinical aspects of all aspect pertaining to blood based medicine including but not limited to: Transfusion Medicine; Blood collection, Donor issues, Transmittable diseases, and Blood banking logistics; Immunohematology; Artificial and alternative blood based

\section{Dovepress}

therapeutics; Hematology; Biotechnology/nanotechnology of blood related medicine; Legal aspects of blood medicine; Historical perspectives. The manuscript management system is completely online and includes a very quick and fair peer-review system. Visit http://www.dovepress.com/testimonials.php to read real quotes from published authors. 